\title{
Gold-Rhodium Nanoflowers for the Plasmon-Enhanced Hydrogen Evolution Reaction under Visible Light
}

\section{de Souza Rodrigues, Maria Paula}

2021-11-05

de Souza Rodrigues, M P , Dourado , A H B , Cutolo , L D O , Parreira , L S , Alves , T V , Slater, T J A , Haigh , S J , Camargo , P H C \& Cordoba de Torresi , S I 2021 , ' Gold-Rhodium Nanoflowers for the Plasmon-Enhanced Hydrogen Evolution Reaction under Visible Light ' , ACS catalysis , vol. 11, no. 21 , pp. 13543-13555 . https://doi.org/10.1021/acscatal.1c02938

http://hdl.handle.net/10138/337023

https://doi.org/10.1021/acscatal.1c02938

cc_by

publishedVersion

Downloaded from Helda, University of Helsinki institutional repository.

This is an electronic reprint of the original article.

This reprint may differ from the original in pagination and typographic detail.

Please cite the original version. 


\section{Gold-Rhodium Nanoflowers for the Plasmon-Enhanced Hydrogen Evolution Reaction under Visible Light}

Maria Paula de Souza Rodrigues, André H. B. Dourado, Leonardo de O. Cutolo, Luanna S Parreira, Tiago Vinicius Alves, Thomas J. A. Slater, Sarah J. Haigh, Pedro H. C. Camargo,* and Susana Inés Cordoba de Torresi*

Cite This: ACS Catal. 2021, 11, 13543-13555

Read Online

ACCESS | Lلll Metrics \& More | 回 Article Recommendations | st Supporting Information

ABSTRACT: State of the art electrocatalysts for the hydrogen evolution reaction (HER) are based on metal nanoparticles (NPs). It has been shown that the localized surface plasmon resonance (LSPR) excitation in plasmonic NPs can be harvested to accelerate a variety of molecular transformations. This enables the utilization of visible light as an energy input to enhance HER performances. However, most metals that are active toward the HER do not support LSPR excitation in the visible or near-IR ranges. We describe herein the synthesis of gold-rhodium coreshell nanoflowers (Au@Rh NFs) that are composed of a core made up of spherical Au NPs and shells containing Rh branches. The Au@Rh NFs were employed as a model system to probe how the LSPR excitation from Au NPs can lead to an enhancement in the HER performance for Rh. Our data demonstrate that the LSPR excitation at $533 \mathrm{~nm}$ (and 405

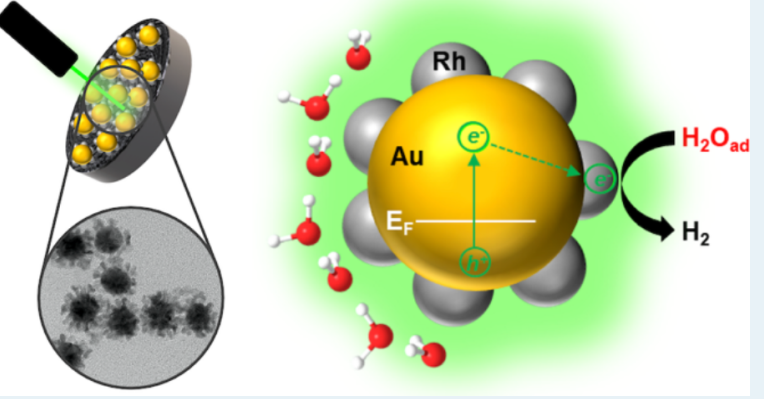
$\mathrm{nm}$ ) leads to an improvement in the HER performance of Rh, which depends on the morphological features of the Au@Rh NFs, offering opportunities for optimization of the catalytic performance. Control experiments indicate that this improvement originates from the stronger interaction of $\mathrm{Au} @ \mathrm{Rh}$ NFs with $\mathrm{H}_{2} \mathrm{O}$ molecules at the surface, leading to an icelike configuration, which facilitated the HER under LSPR excitation.

KEYWORDS: gold, rhodium, nanoflowers, plasmonic catalysis, hydrogen evolution reaction

\section{INTRODUCTION}

Hydrogen $\left(\mathrm{H}_{2}\right)$ represents one of the most promising energy carriers to address challenges related to renewable energy. ${ }^{1} \mathrm{H}_{2}$ production from electrochemical water splitting has attracted massive interest in the past few years. ${ }^{2,3}$ Although electrochemical water splitting is straightforward in principle, it only represents $4 \%$ of the global $\mathrm{H}_{2}$ production due to its high cost and low efficiency. ${ }^{4,5}$ The water-splitting reaction encompasses $\mathrm{H}_{2}$ and $\mathrm{O}_{2}$ production through the hydrogen evolution reaction (HER) and oxygen evolution reaction (OER), respectively. ${ }^{6}$ In this context, noble-metal NPs have been successfully employed as electrocatalysts for $\mathrm{H}_{2}$ generation via the HER, in which Pt-based catalysts represent the state of the art. $^{7-9}$ Nevertheless, due to the associated high costs and low abundance of noble metals there is a strong drive for further improving their activity. ${ }^{10}$

Strategies to improve the performance of noble-metal NPs toward the HER involve size and shape control, bimetallic compositions, and a wealth of hybrid systems. ${ }^{11-13}$ It has been recently established that the localized surface plasmon resonance (LSPR) excitation in plasmonic NPs can be harnessed to accelerate and drive a variety of chemical and electrochemical reactions. ${ }^{14-17}$ When plasmonic NPs support- ing LSPR excitation in the visible range, such as gold $(\mathrm{Au})$ and silver (Ag), are employed, the use of sunlight as a sustainable energy source to drive and accelerate chemical reactions becomes possible. ${ }^{18,19}$ Unfortunately, metals that are active toward the HER, such as platinum $(\mathrm{Pt})$, palladium $(\mathrm{Pd})$, rhodium (Rh), and iridium (Ir), do not support LSPR excitation in the visible range, while $\mathrm{Au}$ and $\mathrm{Ag}$ NPs are not among the most active metals toward the HER. ${ }^{20-23}$ In this context, several hybrid materials containing both plasmonic and catalytic components have been described for the enhancement of photocatalytic activities toward several transformations in both solution and gas phases. ${ }^{10,17,24-28}$ This includes several reduction, oxidation, and coupling reactions, for example. ${ }^{29-34}$ This also includes examples of photoelectrochemical water splitting. ${ }^{35-39}$ This strategy

Received: June 30, 2021

Revised: October 8, 2021

Published: October 25, 2021 
enables the marrying of plasmonic and catalytic properties, in which the plasmonic material acts as an antenna harvesting energy from light through the LSPR excitation and the catalytic component uses this energy to drive or accelerate a transformation of interest. ${ }^{40,41}$ Thus, it becomes clear that this approach can also be beneficial in the context of improving HER performances and enabling renewable energy input (sunlight) and low overpotentials.

We report on the controlled synthesis of gold-rhodium core-shell nanoflowers (Au@Rh NFs) that are comprised of a spherical Au nanoparticle (NP) core and a shell containing Rh branches or small NPs. This material was employed as a model system to probe how the LSPR excitation from the Au NPs can lead to an enhancement in the catalytic activity of the $\mathrm{Rh}$ in the shells toward the HER. While this approach has been demonstrated on several plasmonic-catalytic combinations, examples containing $\mathrm{Rh}$ and exploring the bimetallic plasmonenhanced catalytic activity remain limited. ${ }^{42-46}$ Nevertheless, $\mathrm{Rh}$ has important catalytic properties toward a wealth of transformations that would benefit from plasmonic enhancement and control. ${ }^{47,48}$ Although the synthesis of Au@Rh core-shell NPs has been reported, ${ }^{44-46}$ applications have focused on the HER and not on the effect of plasmonic excitation on HER performances, indicating the need of a deeper understanding of the HER under light irradiation. Here, by employing the HER as a proof of concept transformation, it was demonstrated that the LSPR excitation at $533 \mathrm{~nm}$ (and $405 \mathrm{~nm}$ ) led to an improvement in the HER performance. Our control experiments indicate that this improvement originated from the stronger interaction of $\mathrm{Au} @ \mathrm{Rh}$ NFs with $\mathrm{H}_{2} \mathrm{O}$ molecules at the surface, leading to an icelike configuration, which facilitated the HER under LSPR excitation. The catalytic behavior was found to be dependent on the morphological and compositional features of the Au@Rh NFs, offering future opportunities for optimizing the performance by tuning the morphology, structure, and composition.

\section{EXPERIMENTAL SECTION}

Materials and Methods. All of the reagents were used without further purification: tetrachloroauric(III) acid trihydrate $\left(\mathrm{HAuCl}_{4} \cdot 3 \mathrm{H}_{2} \mathrm{O}, 99 \%\right.$ Sigma-Aldrich), rhodium chloride $\left(\mathrm{RhCl}_{3}, 98 \%\right.$, Sigma-Aldrich), hexadecyltrimethylammonium bromide ( $\mathrm{CTAB}, \mathrm{C}_{19} \mathrm{H}_{42} \mathrm{BrN}$, 99\% Sigma-Aldrich), sodium citrate trihydrate $\left(\mathrm{C}_{6} \mathrm{H}_{5} \mathrm{Na}_{3} \mathrm{O}_{7} \cdot 3 \mathrm{H}_{2} \mathrm{O}, 99 \%\right.$ Sigma-Aldrich), Lascorbic acid $\left(\mathrm{C}_{6} \mathrm{H}_{8} \mathrm{O}_{6}, \geq 99 \%\right.$ BioXtra, Sigma-Aldrich), potassium hydroxide ( $\mathrm{KOH}, 90 \%$ Sigma-Aldrich), sodium iodide (NaI, 99.5\% Sigma-Aldrich), sodium bromide ( $\mathrm{NaBr}$, 99\% Synth), sodium chloride ( $\mathrm{NaCl}, 99 \%$ Synth), polyvinylpyrrolidone (PVP, Sigma-Aldrich, MW $10000 \mathrm{~g} \mathrm{~mol}^{-1}$ ), tetrabutylammonium bromide (TBAB, $\mathrm{C}_{16} \mathrm{H}_{36} \mathrm{BrN}, 98 \%$ Sigma-Aldrich), sodium borohydride $\left(\mathrm{NaBH}_{4}, 98 \%\right.$ SigmaAldrich), hydroquinone $\left(\mathrm{C}_{6} \mathrm{H}_{6} \mathrm{O}_{2}, 99.5 \%\right.$, Sigma-Aldrich $)$, Nafion 5\% $\left(\mathrm{C}_{7} \mathrm{HF}_{13} \mathrm{O}_{5} \mathrm{~S} \cdot \mathrm{C}_{2} \mathrm{~F}_{4}, 15-20 \%\right.$, Sigma-Aldrich $)$, 2propanol $\left(\mathrm{C}_{3} \mathrm{H}_{8} \mathrm{O}, 99.9 \%\right.$ hypergrade for LC-MS LiChrosolv, Merck), and Carbon Vulcan XC-72R. All aqueous solutions were prepared with Millipore water (18.2 M $\Omega$ ).

Instrumentation. High-resolution transmission electron microscopy (HRTEM) images and initial energy dispersive Xray (EDX) spectra were taken on a JEOL JEM 2100 instrument operating at an accelerating voltage of $200 \mathrm{kV}$. The catalysts were redispersed in isopropanol by centrifugation and ultrasound bath agitation and then drop-cast onto transmission electron microscopy (TEM) grids (Formvar/
Carbon Film coated, 200 mesh, $\mathrm{Cu}$ ) and dried under ambient conditions. A JEOL ARM300F instrument was used to acquire high-angle annular dark field (HAADF) scanning transmission electron microscope (STEM) images and EDX spectrum images at a $300 \mathrm{kV}$ accelerating voltage. EDX data were acquired using an Oxford Instruments XMAX 100 detector. HAADF-STEM images were acquired with an inner detector semiangle of $77 \mathrm{mrad}$. UV-vis spectra were recorded on a Shimadzu UV-2600 spectrophotometer. The samples were suspended in water and placed in quartz cuvettes with an optical path of $1 \mathrm{~cm}$. The metallic content of the suspension and deposited materials was measured by inductively coupled plasma atomic emission spectroscopy (ICP-OES) on a Spectro Arcos instrument.

Synthesis of Gold Nanoparticles (Au NPs). First, $30 \mathrm{~mL}$ of distilled water and $300 \mu \mathrm{L}$ of $\mathrm{AuCl}_{4}^{-}$(aq) $\left(25 \mathrm{mmol} \mathrm{L}{ }^{-1}\right)$ were placed in a round-bottom flask and the flask was placed on a heating plate with stirring at $130{ }^{\circ} \mathrm{C}$. When the mixture was boiling, $900 \mu \mathrm{L}$ of a sodium citrate solution $(38.7 \mathrm{mmol}$ $\mathrm{L}^{-1}$ or $\left.1 \%\right)$ was added and the reaction proceeded for $10 \mathrm{~min}$. Finally, the red suspension obtained was washed by successive rounds of centrifugation and removal of the supernatant and then concentrated to $4 \mathrm{mmol} \mathrm{L}^{-1}$ (concentration given in terms of $\mathrm{Au}$ content). The suspension concentration was determined by inductively coupled plasma atomic emission spectroscopy (ICP-OES). The as-produced Au NPs had a diameter of $14.8 \pm 1 \mathrm{~nm}$ as measured by TEM (Figure S1a).

Synthesis of Rhodium Nanoparticles (Rh NPs) as Controls for the Electrochemical Studies. A $3.70 \mathrm{mg}$ portion of $\mathrm{NaBH}_{4}, 9.3 \mathrm{mg}$ of $\mathrm{RhCl}_{3}$, and $87 \mathrm{mg}$ of PVP 10000 were weighed and transferred to a milling jar. The milling experiments were conducted with a $14 \mathrm{~mL}$ PTFE milling jar using three $\mathrm{ZrO}_{2}$ balls $(10 \mathrm{~mm}, 3.17 \mathrm{~g}$ each), giving a ball to powder mass ratio (bpr) of 95:1. The milling device consists of a vibrating ball mill with a fixed vibration frequency of $27.5 \mathrm{~Hz}$ (SL-38, SOLAB-Brazil). The Rh nanoparticles were obtained after $1 \mathrm{~h}$ of milling and had a diameter of $2 \mathrm{~nm}$ as determined by TEM (Figure S1b).

Synthesis of Gold-Rhodium Nanoflowers (Au@Rh NFs). A $0.1 \mathrm{~g}$ portion of CTAB, TBAB, or PVP was placed in a round-bottom flask containing $18.6 \mathrm{~mL}$ of distilled water. This mixture was sonicated for $5 \mathrm{~min}$ and heated to $90{ }^{\circ} \mathrm{C}$ with stirring. After $5 \mathrm{~min}, 1 \mathrm{~mL}$ of the previously prepared Au NP suspension $\left(4 \mathrm{mmol} \mathrm{L}^{-1}\right), 50 \mu \mathrm{L}$ of an aqueous $\mathrm{NaI}, \mathrm{NaBr}$, or $\mathrm{NaCl}$ solution $\left(0.01 \mathrm{~mol} \mathrm{~L}^{-1}\right)$, and a specific volume $(150,350$, 550 , or $750 \mu \mathrm{L})$ of a $\mathrm{RhCl}_{3}$ aqueous solution $\left(20 \mathrm{mmol} \mathrm{L}^{-1}\right)$ were added to the reaction mixture. The amount of $\mathrm{Rh}$ was varied to investigate how the NF morphology and the plasmonic-catalytic properties changed as a function of the Rh content. After $5 \mathrm{~min}, 1 \mathrm{~mL}$ of ascorbic acid, $\mathrm{NaBH}_{4}$, or hydroquinone solution $\left(0.04 \mathrm{~mol} \mathrm{~L}^{-1}\right)$ was added, and the reaction was allowed to proceed for $30 \mathrm{~min}$. The brownish black solution obtained (Figure S2) was washed by successive rounds of centrifugation and removal of the supernatant and deposited on a Carbon Vulcan support by wet impregnation for further electrochemical measurements. After deposition on the Carbon Vulcan support, all samples were analyzed by ICPOES and the metal loading in all cases was around $2 \%$.

HER Experiments. Electrochemical testing was performed with an electrochemical cell consisting of a reversible hydrogen electrode (RHE) reference and a Pt wire as the auxiliary electrode. The working electrode was a glassy-carbon-disk electrode $(d=1.5 \mathrm{~mm})$ modified by drop-casting $10 \mu \mathrm{L}$ of 

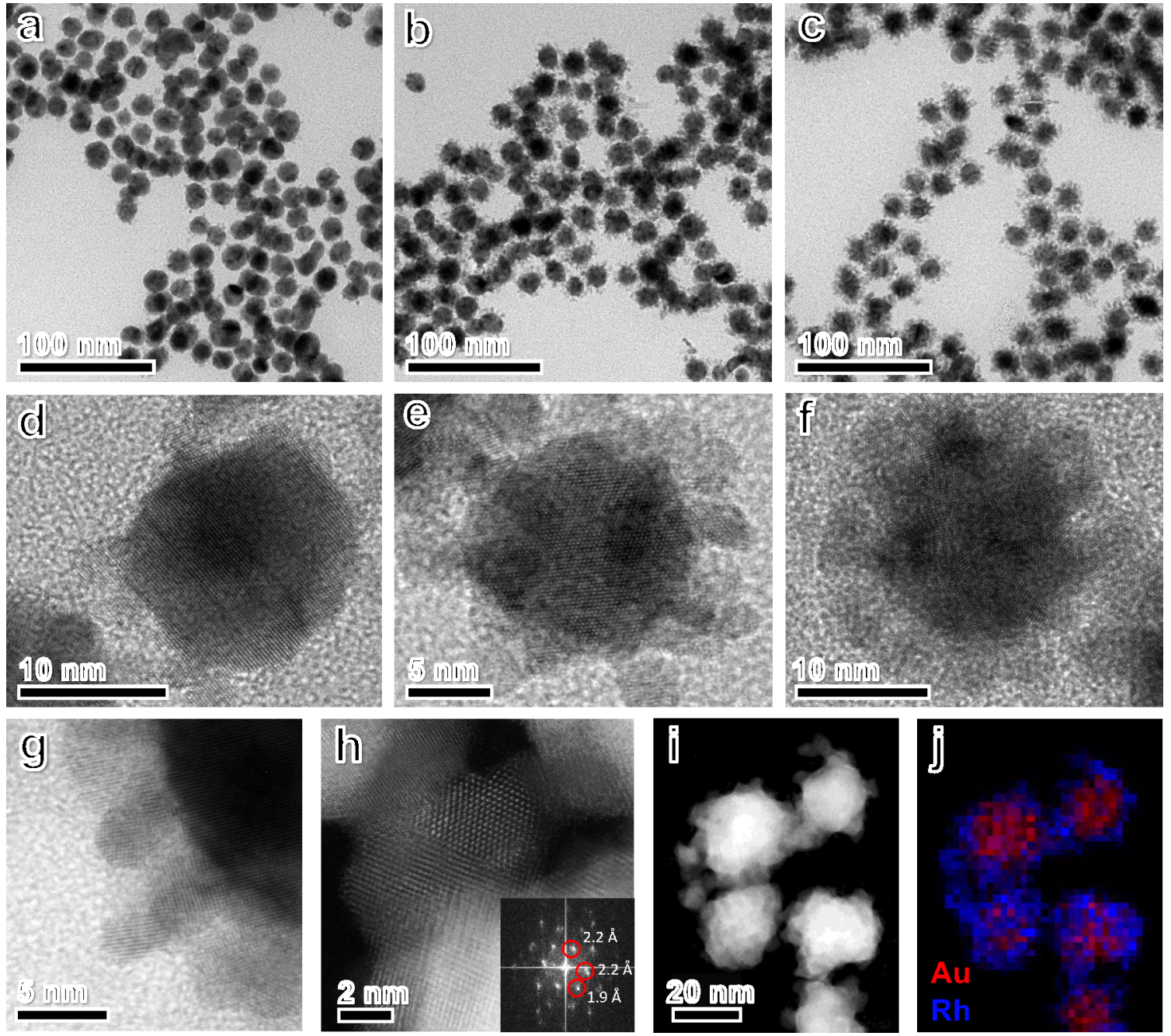

Figure 1. TEM and HRTEM images for (a, d) $\mathrm{Au}_{90} \mathrm{Rh}_{10}$, (b, e) $\mathrm{Au}_{82} \mathrm{Rh}_{18}$, and (c, f, g) $\mathrm{Au}_{68} \mathrm{Rh}_{32}$ NFs. (h, i) HAADF-STEM images for $\mathrm{Au}_{68} \mathrm{Rh}_{32}$ NFs. The inset in (h) is the FFT that shows $d$ spacings consistent with $\{111\}(2.2 \AA)$ and $\{200\}$ (1.9 $\AA$ ) lattice planes in Rh, as would be expected when a particle is viewed along the $\langle 110\rangle$ zone axis. (j) STEM-EDX elemental maps from the region shown in $(i)$ for the $\mathrm{Au}_{68} \mathrm{Rh}_{32} \mathrm{NFs} \mathrm{The}$ elemental distributions of $\mathrm{Au}$ and $\mathrm{Rh}$ are shown in red and blue, respectively. The scale bar in (i) also applies to (j).

catalyst ink ( $5 \mathrm{mg}$ of the catalyst dispersed in $2 \mathrm{~mL}$ of water) and $5 \mu \mathrm{L}$ of a Nafion $0.05 \%$ solution. The electrolyte was 1 mol L ${ }^{-1} \mathrm{KOH}$ solution, and the cell was $\mathrm{N}_{2}$-saturated to avoid the formation of reactive oxygen species. A hydrodynamic condition of $1600 \mathrm{rpm}$ controlled by a Pine AFMSRCE RDE apparatus was used to avoid accumulation of hydrogen bubbles on the electrode surface. To investigate the catalyst HER performance, linear potential, triangular potential, and potential step perturbations were executed and controlled by a PGSTAT302N Autolab potentiostat/galvanostat. For the light-driven experiments, modular lasers of 405, 533, and 650 $\mathrm{nm}$ of 300,200 , and $390 \mathrm{~mW} \mathrm{~cm}^{-2}$ power density, respectively, were positioned $5 \mathrm{~cm}$ from the cell. The laser was turned on 5 min before starting the measurement, to avoid power fluctuation. The perturbation programs were the same as those under dark conditions. The electrochemically active surface area (ECSA) was estimated from the electrochemical double-layer capacitance from each catalyst. Cyclic voltammograms were recorded at several scan rates $\left(10-1000 \mathrm{mV} \mathrm{s}^{-1}\right)$ from 0 to $0.6 \mathrm{~V}_{\mathrm{RHE}}$. The double-layer capacitance $\left(C_{\mathrm{dl}}\right)$ was calculated from the slope of the current (at $0.30 \mathrm{~V}_{\mathrm{RHE}}$ ) versus scan rate linear plots. The $C_{\mathrm{dl}}$ values of the catalysts were divided by the $C_{\mathrm{dl}}$ value of pure Carbon Vulcan, as the support also makes a contribution to the surface area.

In Situ Fourier Transform Infrared (FTIR) Spectroscopy. An electrochemical thin-layer cell with a $\mathrm{CaF}_{2}$ window was used in the spectroelectrochemical experiments, using a reversible hydrogen electrode (RHE) as a reference electrode and $\mathrm{Au}$ foil surrounding the working electrode as an auxiliary electrode. The working electrode was a shiny Au disk $(d=5$ $\mathrm{mm})$, modified by the same procedure described in the electrochemical methods. The cell was continuously purged with $\mathrm{N}_{2}$, and the electrolyte used was $1 \mathrm{~mol} \mathrm{~L}^{-1} \mathrm{KOH}$. The experiments were performed in a reflection absorption setup (IRRAS) with a Nicolet 6700 spectrometer (MCT-B detector, gain of $8,4 \mathrm{~cm}^{-1}$ resolution, 64 accumulations), and the potential perturbation was controlled by a PGSTAT302N Autolab potentiostat/galvanostat. The open-circuit potential (OCP) was measured for $5 \mathrm{~min}$, and potential step perturbations were applied from the OCP to $-0.24 \mathrm{~V}_{\mathrm{RHE}}$ during each spectrum acquisition.

X-ray Photoelectron Spectroscopy (XPS) Experiments. The X-ray photoelectron spectroscopy measurements were performed with a Specs FlexPS system equipped with a Phoibos 150 2D CCD detector and a XR50 X-ray source with 
a nonmonochromatic $\mathrm{Al} \mathrm{K} \alpha(1486.61 \mathrm{eV})$ source. The catalyst ink was drop-casted over a $\mathrm{Si}$ substrate, entirely covering the surface, as no $\mathrm{Si}$ signal (the main transition for $\mathrm{SiO}_{2}$ is $\mathrm{Si}_{2 \mathrm{p}}$ at $103.3 \mathrm{eV})^{49}$ was detected. All spectra were registered in a highvacuum chamber at pressures below $10^{-9}$ mbar and were corrected by the $\mathrm{C}_{1 \mathrm{~s}}$ signal $(284.5 \mathrm{eV}) .{ }^{49,50}$

\section{RESULTS AND DISCUSSION}

Synthesis of Au@Rh NFs and LSPR Enhanced HER Performances. The synthesis of gold-rhodium nanoflowers (Au@Rh NFs) was performed by a seeded growth approach using preformed $\mathrm{Au}$ NPs as physical templates for the deposition of different $\mathrm{Rh}$ amounts on their surface. Figure 1a-c shows TEM images for the Au@Rh NFs obtained by the addition of 150,350 , and $550 \mu \mathrm{L}$ of $20 \mathrm{mmol} \mathrm{L}^{-1} \mathrm{RhCl}_{3}$, respectively, to the reaction mixture. The $\mathrm{Rh}$ atomic percentages in the Au@Rh NFs was determined by EDX and correspond to 10 (Figure 1a), 18 (Figure $1 \mathrm{~b}$ ), and 32 at. \% (Figure 1c). These samples were therefore denoted as $\mathrm{Au}_{90} \mathrm{Rh}_{10}$ (Figure 1a), $\mathrm{Au}_{82} \mathrm{Rh}_{18}$ (Figure $1 \mathrm{~b}$ ), and $\mathrm{Au}_{68} \mathrm{Rh}_{32}$ (Figure 1c). It can be observed that all of the samples were relatively monodisperse, and the size of the NFs corresponded to around $19.3 \pm 2,22.9 \pm 2$, and $23.8 \pm 1 \mathrm{~nm}$ for samples $\mathrm{Au}_{90} \mathrm{Rh}_{10}$ (Figure 1a), $\mathrm{Au}_{82} \mathrm{Rh}_{18}$ (Figure $1 \mathrm{~b}$ ), and $\mathrm{Au}_{68} \mathrm{Rh}_{32}$ (Figure 1c), respectively. Histograms of the size distribution are shown in Figure S3. The increase in size correlates with the increased amount of $\mathrm{RhCl}_{3}$ added to the synthesis and the higher $\mathrm{Rh}$ content in the NPs, indicating the size increase can be ascribed to an increased $\mathrm{Rh}$ deposition at the Au surface.

This is confirmed by HRTEM images for $A u_{90} \mathrm{Rh}_{10}$ (Figure 1d), $\mathrm{Au}_{82} \mathrm{Rh}_{18}$ (Figure 1e) , and $\mathrm{Au}_{68} \mathrm{Rh}_{32}$ (Figure 1f) $\mathrm{NFs}$. All images show $\mathrm{Au}$ cores $(\sim 15 \mathrm{~nm}$ diameter $)$ covered in small $\mathrm{Rh}$ NPs ( $\sim 2 \mathrm{~nm}$ in diameter), with the Au and $\mathrm{Rh}$ identifiable by their lattice fringe spacings (e.g., Figure $1 \mathrm{~h}$ ) or using STEMEDS elemental mapping (Figure $1 \mathrm{j}$ ). Figure $1 \mathrm{~d}$ reveals that in the $\mathrm{Au}_{90} \mathrm{Rh}_{10} \mathrm{NFs} \mathrm{Rh}$ is present as individual NP islands or single-crystal branches on the $\mathrm{Au}$ surface. At higher $\mathrm{Rh}$ loadings $\left(\mathrm{Au}_{82} \mathrm{Rh}_{18}\right.$ and $\mathrm{Au}_{68} \mathrm{Rh}_{32}$ in Figure if and Figure 1e, respectively), an increasingly high number of Rh particles or branches covered the Au NPs, yielding an Au@Rh core-shell morphology for the NFs at higher Rh content. Although each individual island/branch appears to be single-crystalline, the tortuous morphology, as illustrated in Figure $1 \mathrm{~g}$ for $\mathrm{Au}_{68} \mathrm{Rh}_{32}$, suggests this is formed by an oriented attachment of separate $\mathrm{Rh}$ particles. It can be observed that each branch/island at the surface is $<5 \mathrm{~nm}$ in diameter and displays lengths of around 5 $\mathrm{nm}$. When the Rh content in the NFs was further increased to generate $\mathrm{Au}_{59} \mathrm{Rh}_{41}$ NFs (Figure S4), the presence of individual Rh NPs was detected in addition to the Au@Rh NFs. This result indicates that, as the $\mathrm{Au}$ surface becomes completely covered with $\mathrm{Rh}$, no further $\mathrm{Rh}$ deposition at the surface of the $\mathrm{Au} @ \mathrm{Rh}$ can take place and the additional Rh NPs remain in solution.

Figure 2 shows the UV-vis extinction spectra registered from an aqueous suspension containing the Au NP seeds and the $\mathrm{Au}_{90} \mathrm{Rh}_{10}, \mathrm{Au}_{82} \mathrm{Rh}_{18}$, and $\mathrm{Au}_{68} \mathrm{Rh}_{32}$ NFs. The Au seed NPs display a band centered at $522 \mathrm{~nm}$ that is assigned to the LSPR dipolar mode. ${ }^{51}$ The intensity of this band decreased with the deposition of $\mathrm{Rh}$ on the surface in $\mathrm{Au}_{90} \mathrm{Rh}_{10} \mathrm{NFs}$, as would be expected due to the suppression of the Au LSPR extinction with the deposition of a nonplasmonic metal at its surface. For $\mathrm{Au}_{82} \mathrm{Rh}_{18}$ and $\mathrm{Au}_{68} \mathrm{Rh}_{32} \mathrm{NFs}$, in addition to a further decrease in the intensity of this band, a red shift to $548 \mathrm{~nm}$ and

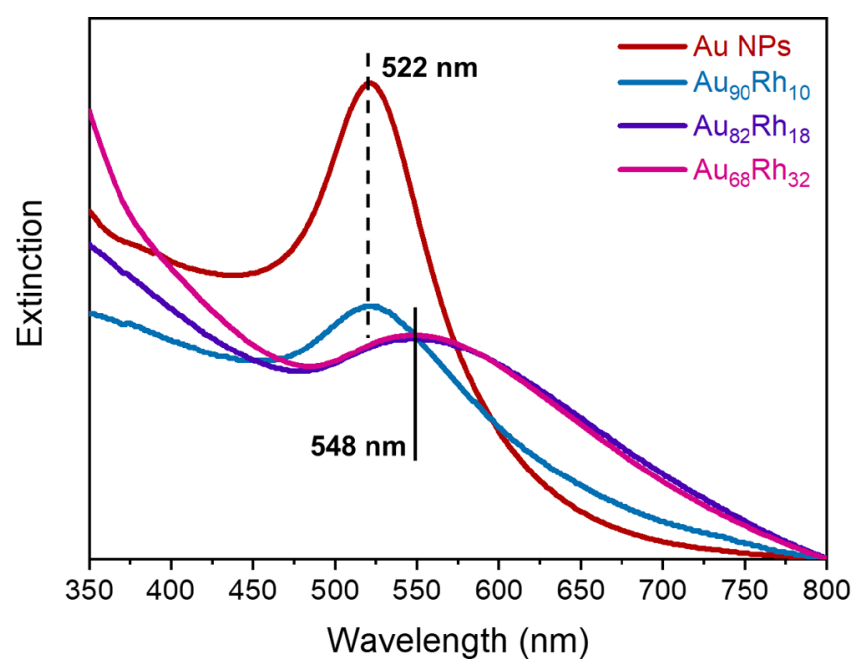

Figure 2. Extinction spectra obtained from aqueous suspensions containing $A u$ NP seeds and from $A u_{90} R_{10}, A u_{82} R_{18}$, and $A u_{68} R_{32}$ NFs.

broadening of the signal are observed. This can be assigned to the change in dielectric constant due to the increased $\mathrm{Rh}$ deposition at the surface. As the overall NF size is also increased, scattering can also contribute to the broadening of the signal. Importantly, all NFs display extinction signals characteristic of the Au LSPR in the visible range, despite the $\mathrm{Rh}$ deposition at the Au surface. ${ }^{52}$ Additionally, an increase in the intensity in the short-wavelength region from 350 to 400 $\mathrm{nm}$ is detected, which scaled with the $\mathrm{Rh}$ content and is assigned to the increasing Rh LSPR in the UV range. ${ }^{53,54}$ The signal in this region can also have contributions of $\mathrm{Au}$ interband transitions below $515 \mathrm{~nm}$.

To further investigate the formation mechanism for the $\mathrm{Au} @ \mathrm{Rh}$ NFs, we performed control experiments to unravel the effect of $\mathrm{I}_{\mathrm{aq}}{ }^{-}$and different surfactants on the resulting NF morphology. In the absence of $\mathrm{I}_{\mathrm{aq}}{ }^{-}$ions, the TEM images (Figure S5a) show a core-shell structure, consisting of the $\mathrm{Au}$ NP seed surrounded by a lower-density, uniform shell layer containing the Rh NP seeds but no Rh branches. This result shows that the presence of $\mathrm{I}_{\mathrm{aq}}{ }^{-}$ions is essential to enable the formation of Rh-based branches at the surface of the Au NP seeds. Here, it is plausible that $\mathrm{I}_{\mathrm{aq}}{ }^{-}$can act as a stabilizer of the $\mathrm{Rh}$ surface facets that favor the formation of the branched morphology via oriented attachment. This was further confirmed by replacing $\mathrm{I}_{\mathrm{aq}}{ }^{-}$ions by $\mathrm{Br}_{\mathrm{aq}}{ }^{-}$and $\mathrm{Cl}_{\mathrm{aq}}{ }^{-}$in the synthesis (Figure S5b,c, respectively). While $\mathrm{Br}_{\mathrm{aq}}{ }^{-}$and $\mathrm{Cl}_{\mathrm{aq}}{ }^{-}$ also promoted the deposition of $\mathrm{Rh}$ islands or branches at the $\mathrm{Au}$ NP surface, their morphology was not as uniform and welldefined as in the case of $\mathrm{I}_{\mathrm{aq}}{ }^{-}$ions. As the interaction of $\mathrm{Rh}$ with halides is expected to increase in the order $\mathrm{I}^{-}>\mathrm{Br}^{-}>\mathrm{Cl}^{-},{ }^{55}$ it is plausible that $\mathrm{I}^{-}$would act as a better stabilizer relative to the other halides for $\mathrm{Rh}$ surface facets that favor the deposition of $\mathrm{Rh}$ branches and lead to the morphology of the Au@Rh NFs.

Control experiments replacing $\mathrm{CTAB}$ by $\mathrm{TBAB}$ (Figure S6a) and PVP (Figure S6b) did not lead to the formation of the NFs. This indicates that both $\mathrm{CTAB}$ and $\mathrm{I}_{\mathrm{aq}}{ }^{-}$ions are essential to the synthesis of Au@Rh NFs. The effect of the reducing agent was also investigated by replacing ascorbic acid with $\mathrm{NaBH}_{4}$ (Figure S6c) and hydroquinone (Figure S6d). In both cases, the Au@Rh NF morphology was not detected, illustrating that the use of a mild reducing agent coupled with 
the use of CTAB and $\mathrm{I}_{\mathrm{aq}}{ }^{-}$ions was imperative to the formation of Au@Rh NFs. Although iodide and bromide are known for poising surfaces in catalytic applications, the presence of iodide was not detected by XPS (Figure S7). Although some bromide was detected and could influence the activity (decrease HER performance), it was detected in all samples, indicating that the chemical environment and, thus, the effect would be the same in all cases. This indicates that further optimization of the washing procedure can lead to improvements in the HER activity.

Table S1 summarizes all the experimental conditions that were investigated for the synthesis optimization of $\mathrm{Au} @ \mathrm{Rh}$ NFs. Finally, we monitored the morphological changes and growth evolution as a function of time by stopping the synthesis at different time intervals $(5,10,15$, and $30 \mathrm{~min})$ and analyzing the generated NPs by HRTEM, as shown in Figure S8 for the sample composition $\mathrm{Au}_{59} \mathrm{Rh}_{41}$. As the synthesis time varied from 5 to $30 \mathrm{~min}$, a gradual increase in the deposition of $\mathrm{Rh}$ small islands or branches at the Au NP surface was detected, together with the formation of individual Rh NPs after $30 \mathrm{~min}$. These results indicate that, in addition to the amount of Rh precursor employed during the synthesis, the synthesis time can be employed to control the degree of $\mathrm{Rh}$ deposition at the surface of Au NPs.

Having verified the morphology produced during the synthesis, we then investigated the Au@Rh NFs as model systems to consider how plasmonic effects can influence the materials performance toward the HER. The hypothesis is that the optical/plasmonic properties of the Au core can enhance the $\mathrm{Rh}$ HER performance under visible light illumination via plasmonic electrocatalysis. For the electrochemical experiments the nanostructures were impregnated in Carbon Vulcan to increase the material conductivity. The metallic loading ( $\mathrm{Au}$ $+\mathrm{Rh}$ ) was determined by ICP-OES to be around $2 \%$ in all cases, which for $\mathrm{Au}_{68} \mathrm{Rh}_{32}$ corresponds to $0.06 \mu \mathrm{g}$ of $\mathrm{Rh}$ and $0.14 \mu \mathrm{g}$ of $\mathrm{Au}$. We performed the experiments at $\mathrm{pH} 14$ to avoid corrosion and improve the stability of the catalyst.

We started by recording triangular potential perturbations at $50 \mathrm{mV} \mathrm{s}^{-1}$ from 0 to $1.2 \mathrm{~V}_{\mathrm{RHE}}$ (illustrated schematically in Figure S9a) to evaluate the electrochemical profile for each material, as presented in Figure S9. Peaks between 0 and 0.2 $\mathrm{V}_{\mathrm{RHE}}$ were attributed to the $\mathrm{H}_{2}$ adsorption-desorption reaction $\left(\mathrm{H}_{\text {upd }}\right)$ on $\mathrm{Rh}^{56,57}$ and are noticeable in all three samples tested $\left(\mathrm{Au}_{90} \mathrm{Rh}_{10}, \mathrm{Au}_{82} \mathrm{Rh}_{18}\right.$, and $\left.\mathrm{Au}_{68} \mathrm{Rh}_{32}\right)$. Rh shows a stronger adsorption of hydrogen in comparison to $\mathrm{Au}^{58}$ Thus, as the $\mathrm{Rh}$ ratio increases, so does the $\mathrm{H}_{\text {upd }}$.

Polarization curves at $5 \mathrm{mV} \mathrm{s}^{-1}$ from 0.1 to $-0.3 \mathrm{~V}_{\mathrm{RHE}}$ under hydrodynamic conditions were recorded with and without light illumination at the working electrode for $\mathrm{Au}_{90} \mathrm{Rh}_{10}, \mathrm{Au}_{82} \mathrm{Rh}_{18}$, and $\mathrm{Au}_{68} \mathrm{Rh}_{32}$ NFs, as shown in Figure 3a. Monometallic $\mathrm{Au}$ and Rh seed NPs were also evaluated as reference materials. A green laser $\left(533 \mathrm{~nm}, 200 \mathrm{~mW} \mathrm{~cm}{ }^{-2}\right.$ ) was used as the LSPR excitation source, which was chosen due to its proximity to the extinction band of the NFs (Figure 2). It can be observed that the monometallic $\mathrm{Au}$ and $\mathrm{Rh}$ NPs do not show any difference in activity in the applied potential range for light and dark conditions. An increase in the HER activity is observed as the Rh content of the Au@Rh NFs increases, under both dark and light conditions (Figure 3a,b). The overpotential at $10 \mathrm{~mA}$ $\mathrm{cm}^{-2}$ ECSA $\left(\eta_{10}\right)$ under dark conditions corresponds to 0.25 , 0.20, and $0.17 \mathrm{~V}_{\mathrm{RHE}}$ for $\mathrm{Au}_{90} \mathrm{R}_{10}, \mathrm{Au}_{82} \mathrm{Rh}_{18}$, and $\mathrm{Au}_{68} \mathrm{Rh}_{32} \mathrm{NFs}$, respectively. These data indicate that it is only possible to produce hydrogen in the probed potential range under our
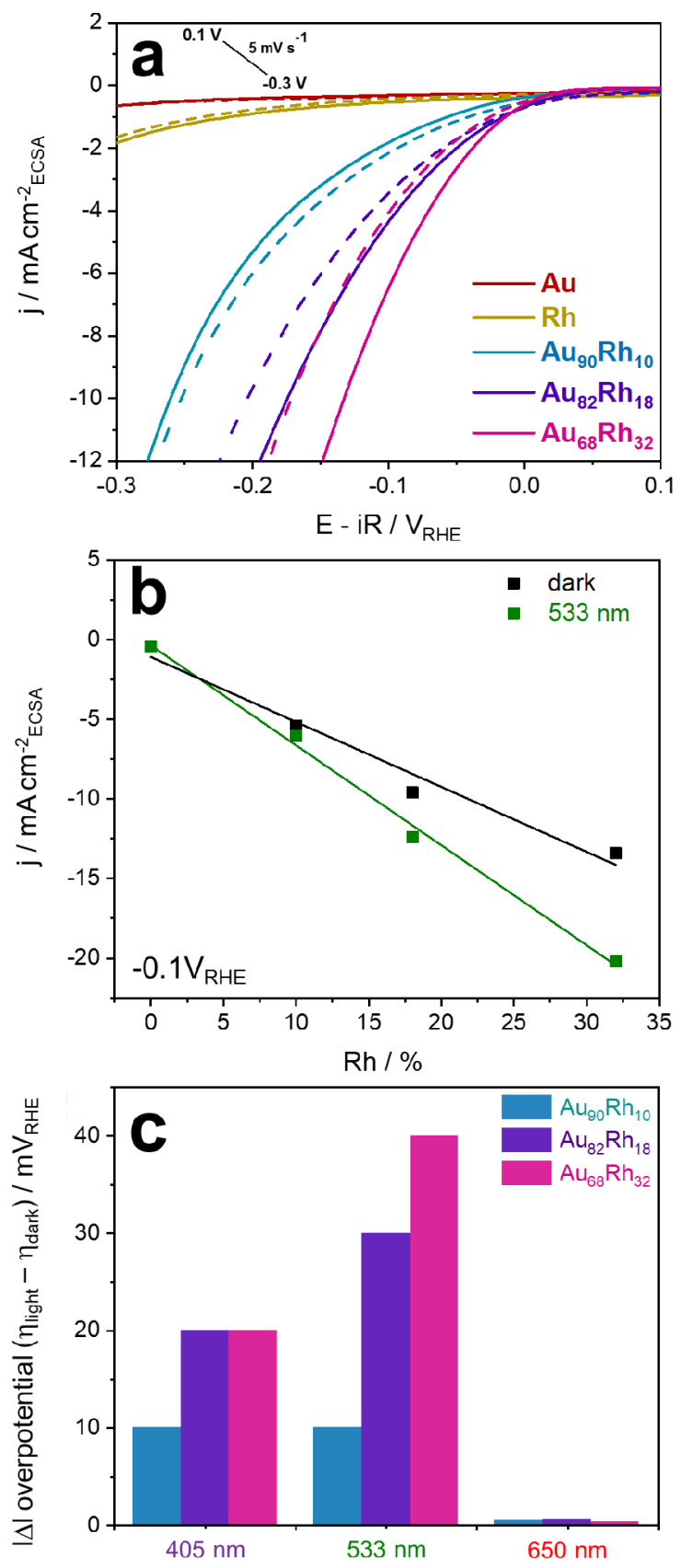

Figure 3. (a) Polarization curves recorded at $5 \mathrm{mV} \mathrm{s}^{-1}$ from 0.1 to $-0.3 \mathrm{~V}_{\mathrm{RHE}}$ for $\mathrm{Au} \mathrm{NPs}, \mathrm{Rh} \mathrm{NPs}$, and $\mathrm{Au}_{90} \mathrm{Rh}_{10}, \mathrm{Au}_{82} \mathrm{Rh}_{18}$, and $\mathrm{Au}_{68} \mathrm{Rh}_{32}$ NFs. Solid traces refer to the curves registered under 533 $\mathrm{nm}\left(200 \mathrm{~mW} \mathrm{~cm}^{-2}\right)$ light excitation, while the dashed traces refer to the experiments performed in the dark. (b) Current density versus $\mathrm{Rh}$ $\%$ for $\mathrm{Au}_{90} \mathrm{Rh}_{10}, \mathrm{Au}_{82} \mathrm{Rh}_{18}$, and $\mathrm{Au}_{68} \mathrm{Rh}_{32}$ NFs in the presence and absence of laser illumination $\left(533 \mathrm{~nm}, 200 \mathrm{~mW} \mathrm{~cm}^{-2}\right)$. (c) Bar graph depicting the wavelength-dependent $|\Delta|$ in overpotentials $\left(\eta_{\text {light }}-\right.$ $\eta_{\text {dark }}, 405,533$, and $650 \mathrm{~nm}$ with power densities of 300,200 , and 390 $\mathrm{mW} \mathrm{cm}{ }^{-2}$, respectively) for $\mathrm{Au}_{90} \mathrm{Rh}_{10}, \mathrm{Au}_{82} \mathrm{Rh}_{18}$, and $\mathrm{Au}_{68} \mathrm{Rh}_{32} \mathrm{NFs}$.

experimental conditions when both metals are coupled in the bimetallic NFs. The LSPR excitation produced by light illumination led to an enhancement in the HER activity in the $\mathrm{Au}_{82} \mathrm{Rh}_{18}$ and $\mathrm{Au}_{68} \mathrm{Rh}_{32} \mathrm{NFs}$, decreasing the $\eta_{10}$ values by 40 and $30 \mathrm{mV}_{\mathrm{RHE}}$, respectively (Figure $3 \mathrm{c}$ ). This corresponds to a decrease in $\eta_{10}$ values of 20 and $18 \%$, respectively. Surprisingly, no changes in the $\eta_{10}$ value were detected for the $\mathrm{Au}_{90} \mathrm{Rh}_{10}$ NFs upon illumination. As the HER studies were 
performed under the same loading of metal $(\mathrm{Au}+\mathrm{Rh})$, and the performance and light enhancement are dependent on the amount of $\mathrm{Rh}$, it is plausible that the electrode must hold a minimum critical concentration of $\mathrm{Rh}$ so that the performance becomes high enough to be sensitive to the LSPR excitation. Under our experimental conditions, our results indicate that $\mathrm{Au} @ \mathrm{Rh}$ NF catalysts showed a better performance than $\mathrm{Au}(111)^{59}$ and commercial $\mathrm{Rh} / \mathrm{C}^{60}$ in alkaline media. However, it is important to note that a more precise comparison would require normalization to the electrochemically active surface area (ECSA) and other experimental conditions, such as laser power density. Moreover, the $\mathrm{Au}_{68} \mathrm{Rh}_{32}$ performance was compared to those of other reported plasmonic catalysts with comparable overpotentials and increase in activity under light excitation. ${ }^{12,61-66}$ Table S2 presents a summary of the HER performances of various materials in alkali and acid electrolytes. It is noteworthy that plasmonic electrocatalysts for the HER are usually reported in acidic media and a higher overpotential is detected at higher $\mathrm{pH}$. Nonetheless, acidic media show some drawbacks that limits their further application, such as corrosion and poor material stability.

We also investigated the dependence of the HER performance on excitation wavelength by employing laser irradiation at 405 and $650 \mathrm{~nm}$ (300 and $200 \mathrm{~mW} \mathrm{~cm}^{-2}$, respetively), as shown in Figure 3c. Neither of these wavelengths is matched to the main Au LSPR extinction band of the NFs (548 nm). As was observed for $533 \mathrm{~nm}$ excitation conditions, the $\mathrm{Au}_{90} \mathrm{Rh}_{10}$ NFs were found to be insensitive to light illumination. For $\mathrm{Au}_{82} \mathrm{Rh}_{18}$ and $\mathrm{Au}_{68} \mathrm{Rh}_{32}$ NFs, no significant changes in the overpotential were detected under $650 \mathrm{~nm}$ excitation compared to dark conditions, as expected. However, under $405 \mathrm{~nm}$ irradiation, a decrease in the overpotential was detected for $\mathrm{Au}_{82} \mathrm{Rh}_{18}$ and $\mathrm{Au}_{68} \mathrm{Rh}_{32}$, although it was a smaller decrease in comparison to that at $533 \mathrm{~nm}$ excitation. This enhancement in HER activity may be due to the partial contribution from the LSPR excitation tail of $\mathrm{Rh}$ at $405 \mathrm{~nm}$ (band maximum in the UV) and interband transitions in $\mathrm{Au}$, which is reflected in the enhanced extinction seen in the UVvis spectra (Figure 2). With regard to the interband transitions, they are observed for Au NPs in the high-energy regime due to direct d-to-s electronic excitation. ${ }^{67}$ It has been reported for some systems that the higher potential of these transitions can lead to higher photocatalytic activities relative to the LSPR (intraband) excitation, as hot electrons can be generated at the $\mathrm{s}$ band and holes can be generated in the d band. ${ }^{67}$ In this case, more hot carriers could generated from direct interband excitation transitions relative to intraband excitations, which may lead to higher photocatalytic activities relative to LSPR excitation. ${ }^{67}$ Therefore, a means to optimize plasmoniccatalytic performances can be obtained by leveraging these transitions.

To further confirm that the enhancement of the HER was due to LSPR excitation (at $530 \mathrm{~nm}$ ) and interband transitions (at $405 \mathrm{~nm}$ ) in the NFs, the on-off $j-t$ transients were recorded under chopped light illumination at both 533 (Figure $4 \mathrm{a}$ ) and $405 \mathrm{~nm}$ (Figure 4b) for the $\mathrm{Au}_{90} \mathrm{Rh}_{10}, \mathrm{Au}_{82} \mathrm{Rh}_{18}$, and $\mathrm{Au}_{68} \mathrm{Rh}_{32}$ NFs. All transients were registered at $-0.1 \mathrm{~V}_{\mathrm{RHE}}$, which is in the Tafel region. It can be observed that all samples present a fast and reproducible current response to on-off illumination cycles. The steady currents under light illumination were wavelength-dependent, being greatest for the $533 \mathrm{~nm}$ excitation. By subtraction of the steady current before $\left(j_{\text {dark }}\right)$
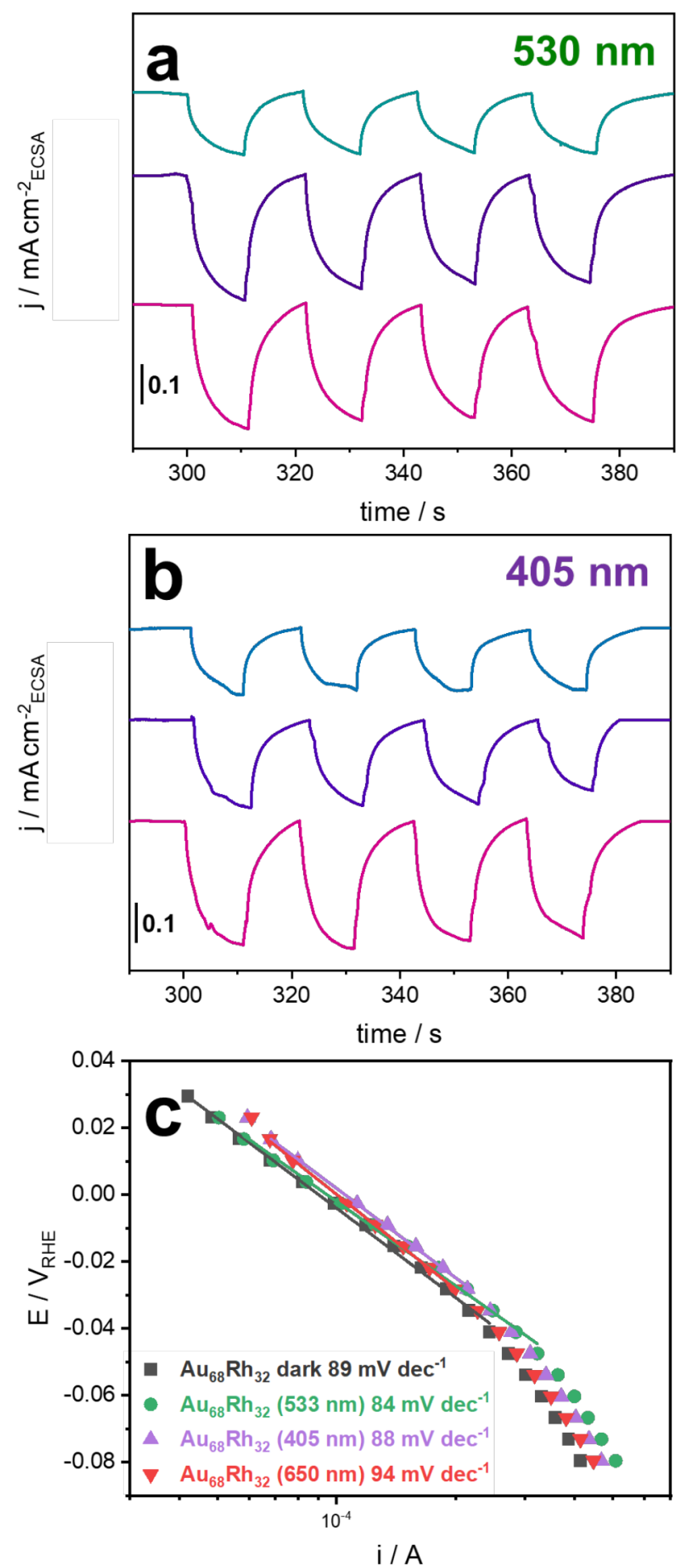

Figure 4. (a, b) On-off $j-t$ transients for $A u_{90} \mathrm{Rh}_{10}, \mathrm{Au}_{82} \mathrm{Rh}_{18}$, and $\mathrm{Au}_{68} \mathrm{Rh}_{32} \quad \mathrm{NFs}$ recorded at $-0.1 \mathrm{~V}_{\mathrm{RHE}}$ with and without light irradiation at 533 and $405 \mathrm{~nm}$, respectively. (c) Tafel plots for $\mathrm{Au}_{68} \mathrm{Rh}_{32} \mathrm{NFs}$ with and without light excitation at 405, 533, and 650 $\mathrm{nm}$ registered in $\mathrm{KOH} 1 \mathrm{~mol} \mathrm{~L}^{-1}$. Laser power densities of 300, 200, and $390 \mathrm{~mW} \mathrm{~cm}^{-2}$ were used for 405,533 , and $650 \mathrm{~nm}$, respectively.

and after $\left(j_{\text {light }}\right)$ the illumination, the photocurrents could be calculated as $0.15,0.27$, and $0.30 \mathrm{~mA} \mathrm{~cm}{ }^{-2}$ ECSA for $\mathrm{Au}_{90} \mathrm{Rh}_{10}$, $\mathrm{Au}_{82} \mathrm{Rh}_{18}$, and $\mathrm{Au}_{68} \mathrm{Rh}_{32}$, respectively, indicating an increase in the photocurrent with the Rh loading.

To gain insights into the mechanism of the HER under light excitation, the Tafel plots for the $\mathrm{Au}_{68} \mathrm{Rh}_{32}$ NFs with and 
without light excitation were obtained from the quasi-steadystate polarization curves, as shown in Figure 4c. The HER mechanism in alkaline medium can be described by the Volmer, Heyrovsky, and Tafel steps, ${ }^{20}$ as shown in eqs $1-3$. The values in parentheses refer to the Tafel slope, which comes from the Tafel equation $(\eta=a \log j)$, where $j$ is the current density and $a$ is the Tafel slope.

$$
\text { Volmer step: } \mathrm{H}_{2} \mathrm{O}+\mathrm{e}^{-} \rightarrow \mathrm{H}_{\mathrm{ads}}+\mathrm{OH}^{-}\left(118.2 \mathrm{mV} \mathrm{dec}^{-1}\right)
$$

$$
\begin{aligned}
& \text { Heyrovsky step: } \mathrm{H}_{2} \mathrm{O}+\mathrm{H}_{\mathrm{ads}}+\mathrm{e}^{-} \\
& \rightarrow \mathrm{H}_{2}+\mathrm{OH}^{-}\left(39.4 \mathrm{mV} \mathrm{dec}{ }^{-1}\right)
\end{aligned}
$$

$$
\text { Tafel step: } \mathrm{H}_{\mathrm{ads}}+\mathrm{H}_{\mathrm{ads}} \rightarrow \mathrm{H}_{2}\left(29.6 \mathrm{mV} \mathrm{dec}^{-1}\right)
$$

These steps represent competitive processes of adsorption/ desorption of hydrogen atoms occurring at the catalyst surface. All steps play a key role necessary to obtain excellent HER performance. $^{20}$ Without light illumination, the average Tafel slope corresponded to $89 \pm 4 \mathrm{mV} \mathrm{dec}^{-1}$. This indicates that the mechanism cannot be explained by a single rate-limiting step (Heyrovsky or Volmer) without further kinetic studies. Intriguingly, there were no significant changes in the Tafel slopes under light illumination, indicating that the HER mechanism remains unchanged under plasmonic excitation, in agreement with previous studies. ${ }^{68}$ These results therefore indicate that the LSPR excitation can lead to enhancements in the HER activity in the Au@Rh NFs, but the HER mechanism remains unchanged.

Investigating the Role of the Bimetallic NF Composition over the Water Adsorption Interactions (under Dark Conditions). It is well-known that HER activity presents a linear relationship with the electrode working function. ${ }^{69-71}$ This relation is due to the generation of adsorbed hydrogen, as presented in the Volmer step and corroborated by DFT simulations. ${ }^{72}$ Even though it is in good agreement with acidic electrolytes, the main problem with this kind of assumption was that for all these investigations high vacuum was needed for the experimental setup or assumed for the simulations. When these proprieties were investigated by a consideration of more realistic environmental conditions, ${ }^{73}$ fine-tuning was possible. A volcano plot was obtained in which several proprieties were considered such as the work needed for a proton transfer from the outer Helmholtz plane (OHP) to the inner plane (IHP), the dessolvation of this proton in the IHP that occurs during the adsorption process, and the charge transfer energy between the metal and the proton for the generation of this adsorbate. In this, Au is present in the weak adsorption branch, presenting a very low activity, while $\mathrm{Rh}$ is close to the volcano top but is already siting at the stronger adsorption branch. This study has also shown that the increase in the work function not only affects the adsorption energy but also influences in the pre-exponential factor of the Arrhenius equation for the HER. This model, however, does not consider in detail the electrolyte-electrode interactions and fails to describe how different materials behave at higher $\mathrm{pH}$ values, since under alkaline conditions, the reactants should be the protons obtained by the water self-ionization or the water molecules themselves, ${ }^{74}$ as shown in eq 1 . Since water should now be considered, it is also important to highlight that the water adsorption conformation ${ }^{75}$ affects the way the $\mathrm{O}-\mathrm{H}$ bond will be more or less easily broken during the Volmer step. $^{74}$ The electrochemical activity dependence on the water adsorption conformation is not new; actually, it was already proposed by Trasatti $^{70}$ for the HER, and it has been shown in the literature that it can affect the electrochemical activity for different reactions. ${ }^{76-78}$ Therefore, it is proposed that the water structure orientation at the double-layer region will give insights into investigations on the HER mechanisms. ${ }^{74}$

Next, we wanted to investigate how the bimetallic composition of the NFs (without light excitation) influence their activities toward the HER. In this case, we were interested in probing if the bimetallic composition could enable different adsorption interactions with water that could lead to improvements in the HER relative to the monometallic NPs. We performed in situ Fourier transform infrared spectroelectrochemistry experiments to gain further insights into the intermediates involved in the hydrogen evolution reaction. These experiments were performed for $\mathrm{Au}_{68} \mathrm{Rh}_{32} \mathrm{NFs}$ and $\mathrm{Au}$ and $\mathrm{Rh}$ NPs, aiming at further understanding the importance of the bimetallic compositions to the improved HER performances in the NFs. The in situ FTIR spectra were recorded under potential step perturbation. Figure 5a shows the spectra obtained for $\mathrm{Au}_{68} \mathrm{Rh}_{32}$ NFs as a function of the applied potential (Figure S10a,b shows the $\mathrm{Au}$ and Rh NPs spectral counterparts, respectively). At approximately 1225 and
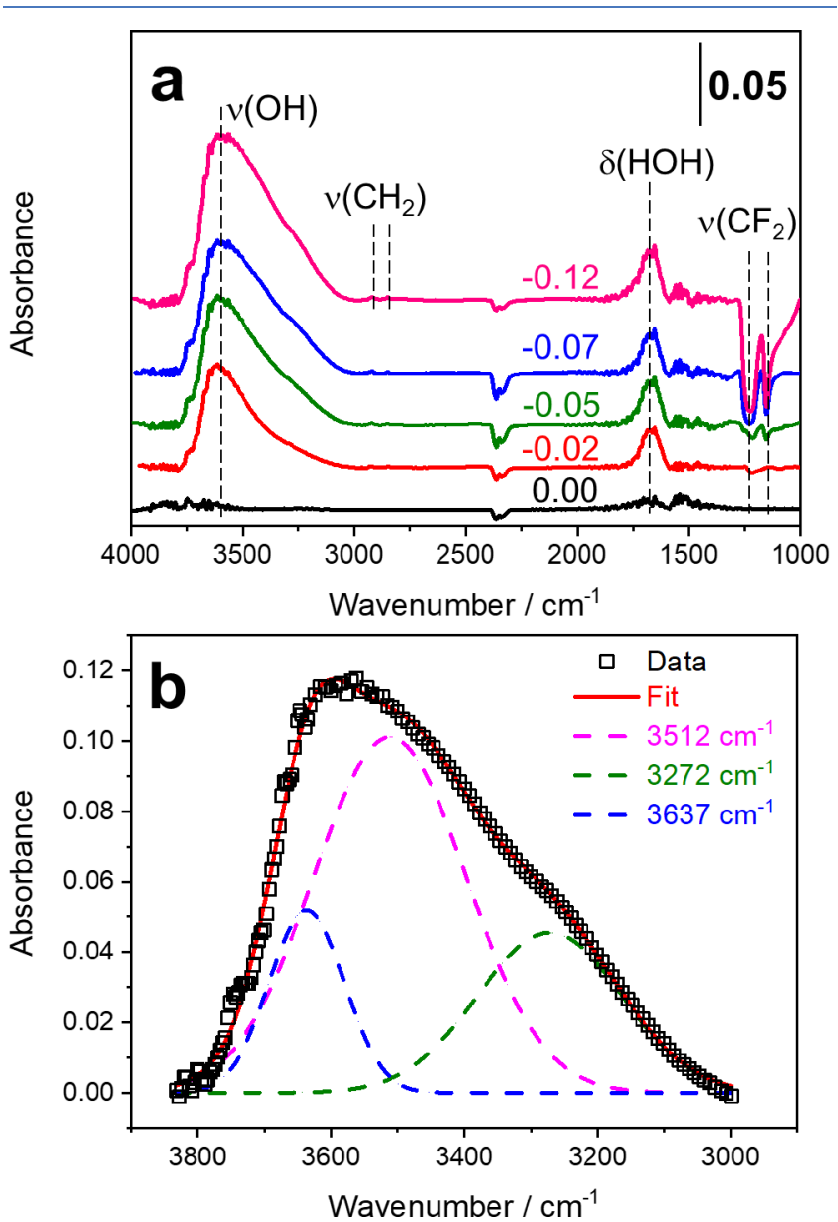

Figure 5. (a) In situ FTIR spectra recorded for $\mathrm{Au}_{68} \mathrm{Rh}_{32}$ NFs during potential step perturbation (as assigned in the figure). (b) Deconvoluted $\sim 3600 \mathrm{~cm}^{-1}$ band at $-0.12 \mathrm{~V}_{\mathrm{RHE}}$ with fitting to peaks at 3512,3272 , and $3637 \mathrm{~cm}^{-1}$. The IR background was taken at open circuit potential (OCP). 

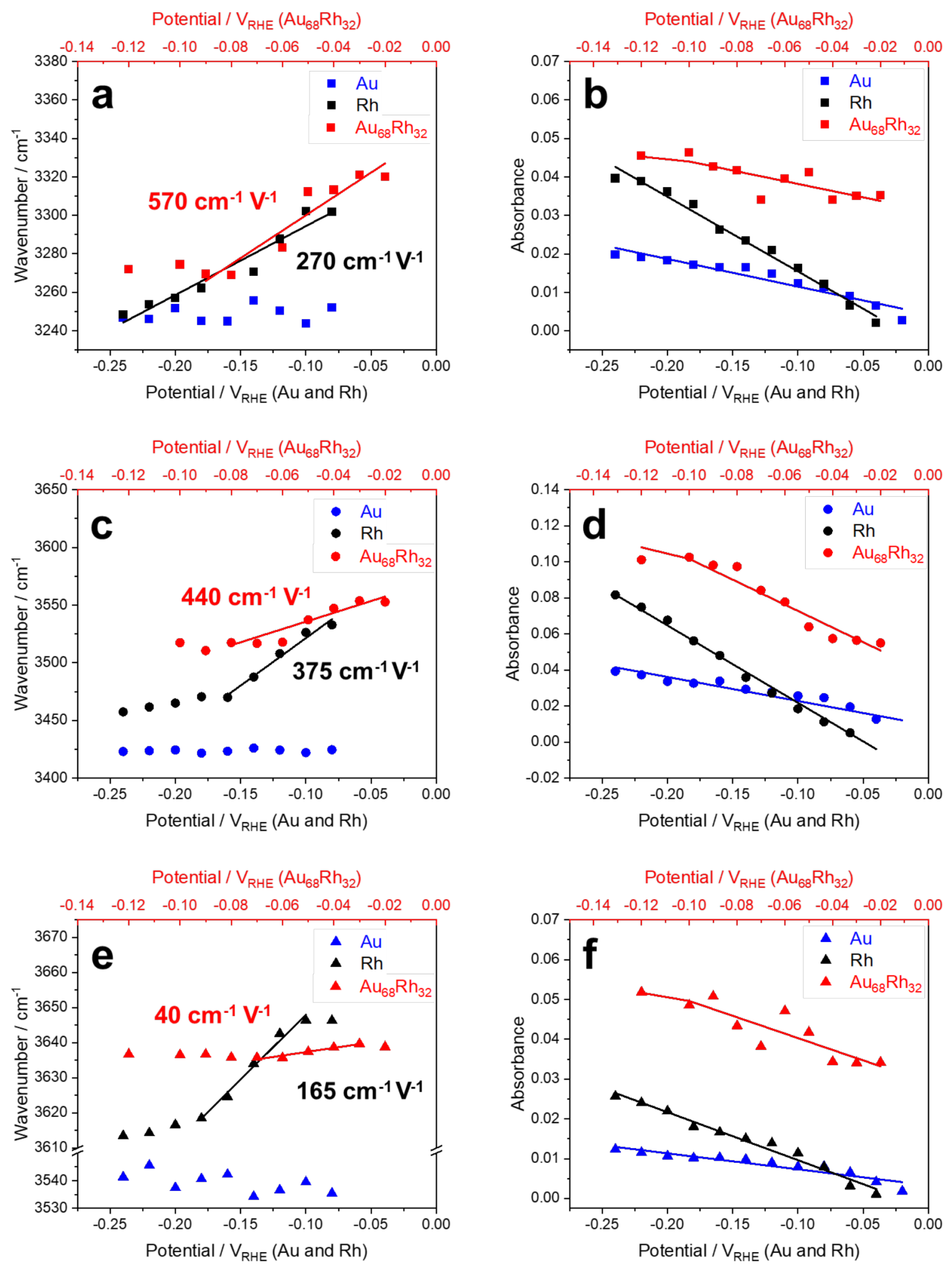

Figure 6. Stark tuning plots and absorbance versus potential plots for deconvoluted bands in the range (a, b) $3240-3320 \mathrm{~cm}^{-1}$, (c, d) $3400-3530$ $\mathrm{cm}^{-1}$, and (e, f) $3530-3650 \mathrm{~cm}^{-1}$ for $\mathrm{Au}, \mathrm{Rh}$, and $\mathrm{Au}_{68} \mathrm{Rh}_{32}$.

$1154 \mathrm{~cm}^{-1}$ two sharp bands are observed, which were assigned to the asymmetric $\left(\nu_{\text {as }}\right)$ and symmetric $\left(\nu_{\mathrm{s}}\right)$ stretching of $\mathrm{CF}_{2}{ }^{79}$ from Nafion. The decrease in the $\mathrm{CF}_{2}$ stretching modes with the potential suggests water incorporation into Nafion. ${ }^{80}$ The bands detected at all potentials at approximately 2920 and $2850 \mathrm{~cm}^{-1}$ were attributed to the asymmetric and symmetric
$\mathrm{CH}_{2}$ stretching modes of an amine from the CTAB. ${ }^{81}$ The bending mode of the adsorbed water $(\delta(\mathrm{HOH}))^{82}$ was observed at 1618, 1664, and $1650 \mathrm{~cm}^{-1}$ in $\mathrm{Au}, \mathrm{Rh}$, and $\mathrm{Au}_{68} \mathrm{Rh}_{32}$, respectively. A lower frequency of $\delta(\mathrm{HOH})$ indicates a stronger water adsorption, as the increase in charge transfer from the oxygen lone pairs decreases the band 
frequency. ${ }^{58}$ Thus, the $\mathrm{Au}_{68} \mathrm{Rh}_{32}$ NFs showed a stronger water adsorption in comparison to $\mathrm{Rh}$, indicating that combining both metals in the nanostructure can improve the catalyst interaction with $\mathrm{H}_{2} \mathrm{O}$. Nonetheless, a direct comparison cannot be made between the bimetallic NFs and $\mathrm{Au}$ NPs, as $\mathrm{Au}$ presents a weaker hydrogen bonding strength, leading the $\delta(\mathrm{HOH})$ band to a lower frequency. ${ }^{58,83}$

The band centered at $\sim 1700 \mathrm{~cm}^{-1}$ for $\mathrm{Au}$ and $\mathrm{Rh}$ NPs (Figure S10a,b) was assigned to the bending mode of the adsorbed hydronium cation $\left(\delta\left(\mathrm{H}_{3} \mathrm{O}^{+}\right)\right)$. More specifically, this corresponds to the interfacial hydronium-water complexes, such as $\mathrm{H}_{5} \mathrm{O}_{2}{ }^{+}, \mathrm{H}_{7} \mathrm{O}_{3}{ }^{+}$, and $\mathrm{H}_{9} \mathrm{O}_{4}{ }^{+} \cdot{ }^{84}$ Although the hydronium complex is not usually observed at higher $\mathrm{pH}$ due to its low concentration, ${ }^{85}$ it can be locally produced during the HER due to the water dissociation process in the electrode at high $\mathrm{pH}^{86}$ As the IR spectrometer in an IRRAS setup has a small optical path and poor mass transport, it can facilitate the observation of reaction intermediates even at low concentrations. This band appeared at higher wavenumber in pure $\mathrm{Rh}$ NPs $\left(1720 \mathrm{~cm}^{-1}\right)$, indicating a stronger interaction in comparison to $\mathrm{Au}$ NPs $\left(1690 \mathrm{~cm}^{-1}\right)$. This bending mode was not detected for $\mathrm{Au}_{68} \mathrm{Rh}_{32} \mathrm{NFs}$; it could be obscured by the $\delta(\mathrm{HOH})$ band. In $\mathrm{Au}$ and $\mathrm{Rh} \mathrm{NPs}$, the $\delta\left(\mathrm{H}_{3} \mathrm{O}^{+}\right)$and $\delta(\mathrm{HOH})$ bands are symmetrical and well-defined. On the other hand, the $\delta(\mathrm{HOH})$ band in $\mathrm{Au}_{68} \mathrm{Rh}_{32}$ had a more asymmetric profile, with a tail toward higher frequencies at higher potentials. This could indicate the presence of more than one band. Nonetheless, as the intensity of this band was low, a deconvolution was not possible.

Moreover, a large band in the $\sim 3100-3800 \mathrm{~cm}^{-1}$ region was attributed to the $\mathrm{OH}$ stretching mode $(\nu(\mathrm{OH}))$ in Figure 5a. This band was deconvoluted into three bands centered at $\sim 3272$, 3512, and $3637 \mathrm{~cm}^{-1}$, with the fitting for $\mathrm{Au}_{68} \mathrm{Rh}_{32} \mathrm{NFs}$ at $-0.12 \mathrm{~V}_{\mathrm{RHE}}$ being shown in Figure $5 \mathrm{~b}$. Stark tuning (wavenumber versus potential) and absorbance versus potential plots are shown in Figures 6.

The Stark plots for Au NPs were constant for all three bands, and no shift in wavenumber was observed in the probed potential range. This indicates that the interaction of Au with adsorbed water is weak for all conformations. The first deconvoluted band centered at 3249, 3268, and $3289 \mathrm{~cm}^{-1}$ (Figure 6a) for $\mathrm{Au}, \mathrm{Rh}$ and $\mathrm{Au}_{68} \mathrm{Rh}_{32}$, respectively, is attributed to an icelike water conformation (Figure S11b). This water conformation has a strongly bonded hydrogen, due to the Fermi resonance of the $\delta(\mathrm{HOH})$ binary overtone and the $\nu(\mathrm{OH}) .{ }^{87}$ The estimated slopes from the Stark tuning plot for this band (Figure 6a) were -270 and $-570 \mathrm{~cm}^{-1} \mathrm{~V}^{-1}$ for $\mathrm{Rh}$ and $\mathrm{Au}_{68} \mathrm{Rh}_{32}$, respectively. Here, the higher the slope, the stronger the interaction between the metal and hydrogen, suggesting adsorption and, consequently, the existence of this water conformation in the IHP. Therefore, these data suggest that the presence of both $\mathrm{Au}$ and $\mathrm{Rh}$ in the bimetallic NFs led to an even stronger interaction with water in comparison to both individual $\mathrm{Au}$ and $\mathrm{Rh}$ NPs. This band increased in intensity with an increased applied potential (Figure 6b), the $\mathrm{Au}$ absorbance variation being smaller than that for the other catalysts as a result of the weaker $\mathrm{H}_{2} \mathrm{O}$ interactions. ${ }^{58}$ The stronger interaction of an icelike water structure with the bimetallic NF could explain its higher catalytic activity in comparison to monometallic $\mathrm{Au}$ and $\mathrm{Rh}$, as the icelike conformation leads to more aligned and oriented water molecules that act as sources of protons due to enhanced water autoprotolysis. ${ }^{88,89}$ In this way, more $\mathrm{H}_{\mathrm{ad}}$ is formed and the Volmer step, which is the initial step and probably one of the limiting steps toward the HER, can be accelerated. In summary, the icelike water conformation could contribute to affecting the electron-transfer chemistry because, as there is more $\mathrm{H}_{\mathrm{ad}}$ in the catalyst surface, the hot electrons could be injected in the adsorbed water molecules and lead to the cleavage of $\mathrm{O}-\mathrm{H}$. If there is more $\mathrm{H}_{\mathrm{ad}}$, this step is then facilitated.

The second deconvoluted band around $3400 \mathrm{~cm}^{-1}$ (Figure $6 \mathrm{c}, \mathrm{d})$ is assigned to hydrogen-bonded water in the bulk, ${ }^{8,90}$ in which water molecules assume a more flat-lying structure (Figure S11a). These bands was centered at 3423, 3482, and $3528 \mathrm{~cm}^{-1}$ for $\mathrm{Au}, \mathrm{Rh}$, and $\mathrm{Au}_{68} \mathrm{Rh}_{32}$, respectively, suggesting a stronger interaction of the water with $\mathrm{Au}_{68} \mathrm{Rh}_{32}$ in comparison to individual $\mathrm{Au}$ and $\mathrm{Rh}$ NPs separately, due to its higher wavenumber. Once more, this band did not shift for Au NPs over the applied potential range, whereas $\mathrm{Rh}$ and $\mathrm{Au}_{68} \mathrm{Rh}_{32}$ showed a shift to higher wavenumbers with the potential. As can be seen in Figure $6 \mathrm{c}, \mathrm{Au}_{68} \mathrm{Rh}_{32}$ also showed a higher slope in the Stark tuning plot $\left(440 \mathrm{~cm}^{-1} \mathrm{~V}^{-1}\right)$ in comparison to the $\mathrm{Au}$ and Rh NPs (0 and $375 \mathrm{~cm}^{-1} \mathrm{~V}^{-1}$, respectively), likely as a result of the stronger interaction. Moreover, the absorbance for this band (Figure 6d) also increased with potential as a result of these surface interactions. It was also suggested in the literature $^{74}$ that water at the third layer (already OHP) already presents a bulk conformation. In this way, the cases in which no Stark effect was observed, this species is probably not interacting directly with the electrode.

Finally, the third deconvoluted bands (Figure 6e,f) were centered at 3537,3628 , and $3637 \mathrm{~cm}^{-1}$ for Au NPs, Rh NPs, and $\mathrm{Au}_{68} \mathrm{Rh}_{32}$ NFs, respectively. These bands correspond to water in the solvation shell of the potassium ions in the electrolyte (Figure S11). ${ }^{76,82,91} \mathrm{Au}$ and $\mathrm{Au}_{68} \mathrm{Rh}_{32}$ showed a similar behavior, with small variations for this band (Figure $6 \mathrm{e})$, indicating that the adsorption of solvated $\mathrm{K}^{+}$ions is weaker for these catalysts. Nonetheless, Rh NPs showed the highest slope in the Stark plots and wavenumber plots (Figure $6 \mathrm{e}, \mathrm{f})$, indicating that the interaction of rhodium with the solvated complex is much stronger in pure Rh NPs. The presence of solvated cations on the electrode can hinder the HER by a steric effect, explaining the higher activity in $\mathrm{Au}_{68} \mathrm{Rh}_{32}$ in comparison to Rh NPs.

These results indicate that the bimetallic composition enables a stronger interaction with water (stronger water adsorption), leading to higher activities relative to the monometallic counterparts. The observation of a preferential water conformation (icelike structure) in the IHP for the most active catalyst indicates that the electron transfer should be facilitated by its presence. It has been proposed in the literature ${ }^{74}$ that in alkaline media electron transfer and water self-ionization are simultaneous steps for the Volmer mechanism. The data presented here help with an understanding of the chemical environment and corroborate the hypothesis presented in the literature about the water conformation and electrode-electrolyte interaction influence on Faradaic processes. However, since dynamic spectroelectrochemical measurements were not possible due to the setup limitations, quantitative data could not be achieved.

Moreover, the light excitation can contribute to further enhance the performance of the bimetallic NFs due to the plasmonic effect. If we compare the activities between the bimetallic NFs and the monometallic samples, our data suggest that the bimetallic composition plays a major role in the 
improvements of performances relative to the LSPR effect, as the increase in activity from the monometallic samples to the bimetallic NFs in the dark is more significant than the additional enhancement provided by the plasmonic excitation.

On the basis of these results, Figure 7 schematically suggests a mechanism for the enhanced HER performances based on

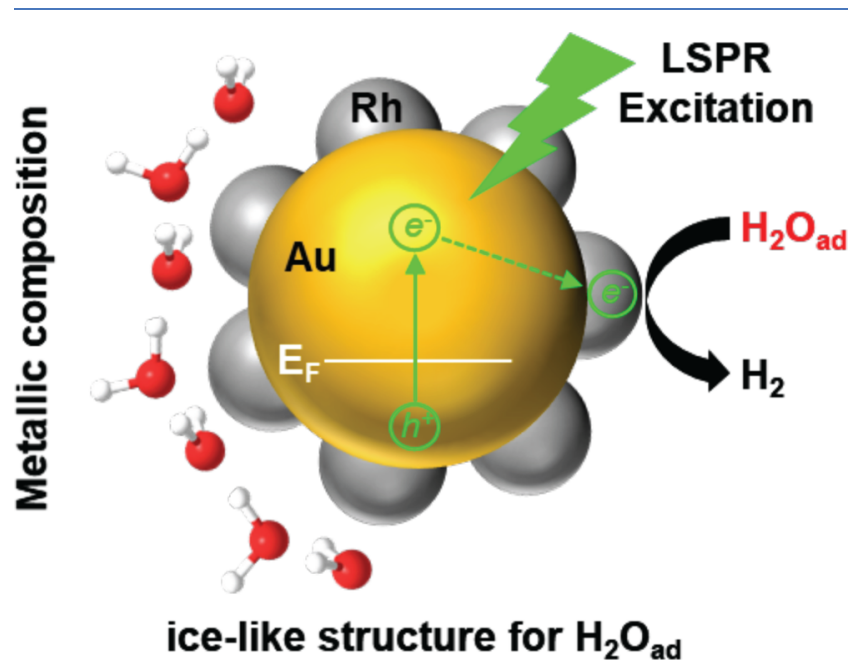

Figure 7. Schematic representation of electron transfer pathways that lead to an enhancement in the HER performances following the LSPR excitation in the Au@Rh NFs. Under 533 nm excitation, hot electrons generated from the Au LSPR excitation can flow to the Rh surface, where they can contribute to the activation of adsorbed $\mathrm{H}_{2} \mathrm{O}$ species, leading to a decrease in the overpotential.

the bimetallic composition and plasmonic effects in the $\mathrm{Au} @$ $\mathrm{Rh}$ NFs. The bimetallic composition contributes to increasing the strength of adsorbed $\mathrm{H}_{2} \mathrm{O}$ at the surface of the NFs, which preferentially leads to an icelike or interfacial water conformation, as suggested by the in situ FTIR. This enables a significant increase in HER performance relative to the monometallic systems, showing that this conformation is favoring the electron transfer simultaneously with the water self-ionization, ${ }^{72,74}$ even in the absence of light excitation. Under $533 \mathrm{~nm}$ light irradiation, hot electrons (and holes) are generated from the LSPR excitation in Au. These hot electrons can flow to the Rh surface, where they can participate in the activation of adsorbed $\mathrm{H}_{2} \mathrm{O}$ species, thus further accelerating the HER and leading to a decrease in the overpotential. In this case, it is expected that this will occur by a photoredox process in which the hot holes are then harvested by the electrolyte. As indicated by the Tafel slope, the limiting steps for the reaction could be Volmer and/or Heyrovsky. Both steps would benefit from hot-electron injection from the Au@Rh NFs. In the case of the Volmer step, the hot electrons would facilitate $\mathrm{H}_{\mathrm{ads}}$ generation, whereas in the Heyrovsky step the hot electrons would directly facilitate the $\mathrm{H}_{2}$ formation. It is important to note that plasmonic catalyst activation has also been reported in the absence of charge transfer via the formation of transient negative ion states. Although this possibility cannot be disregarded herein, the formation of transient negative ion states can deposit vibrational energy in adsorbed water species that could, in turn, contribute to help in their dissociation. ${ }^{19}$ Although the icelike configuration of $\mathrm{H}_{2} \mathrm{O}$ is associated with increased performances under both dark and light illumination conditions, it remains unclear if this state would affect the charge transfer process or vibrational activation of adsorbed water species under plasmonic excitation. Interestingly, under $405 \mathrm{~nm}$ light illumination, hot carries can be generated both from the Au interband excitation and from the excitation of the $\mathrm{Rh}$ LSPR (although this wavelength does not match the maximum $\mathrm{Rh}$ LSPR band). Interband transitions, which produce hot electrons and holes due to excitation from the d-to-s band in $\mathrm{Au}$, can therefore contribute to improving the photoelectrocatalytic activity, leading to an acceleration of the HER, albeit one that is smaller than is observed for $533 \mathrm{~nm}$ light illumination. This indicates that the excitation of interband transitions in this system can also be employed to enhance the rates of the HER. However, under our employed conditions, interband transitions led to a lower enhancement of the HER relative to the LSPR excitation. It is important to note that the $\mathrm{Au}$ and $\mathrm{Rh}$ interface can also play an important role in the charge transfer and subsequent injection of charges to adsorbed water species. This is further evidenced by our simulations on the optical properties (Figure S12), which show that the regions of larger E-field enhancements, under $533 \mathrm{~nm}$ excitation, are concentrated at the junctions between $\mathrm{Rh}$ and $\mathrm{Au}$. These sites are thus expected to contribute to a large optical absorption and charge transfer to adsorbed water species.

\section{CONCLUSION}

We have described herein a facile method for the synthesis of core-shell Au@Rh (antenna@reactor) NFs comprised of spherical Au nanoparticles (NPs) and shells containing Rh islands/branches (smaller than $5 \mathrm{~nm}$ ). The synthesis was performed by seeded growth, and the degree of Rh deposition in the NFs could be tuned by adjusting the amount of Rh precursor employed during the deposition step or controlling the synthesis time. The Au@Rh NFs were employed as a model system to investigate the effect of the LSPR excitation from the Au NPs and their enhancement toward the HER of the Rh shells as a function of the NF composition. Our results demonstrated that the LSPR excitation at $533 \mathrm{~nm}$ led to an improvement in the HER performances. Specifically, NFs containing $68 \mathrm{Au}$ at. $\%$ and $32 \mathrm{Rh}$ at. $\%\left(\mathrm{Au}_{68} \mathrm{Rh}_{32}\right)$ displayed the highest performance toward the HER and plasmonically enhanced HER. Experiments for lower and higher excitation wavelengths confirmed the role of the LSPR excitation toward the HER and suggest that the increase in the HER for the bimetallic NFs relative to the monometallic counterparts was due to a change in the interaction with adsorbed water molecules. In situ FTIR spectra suggested that adsorbed water species assumed an icelike configuration in the bimetallic NFs, thus facilitating the HER. The results presented demonstrate that, although $\mathrm{Rh}$ only supports LSPR in the UV region, plasmonic effects due to visible light irradiation can be harvested to enhance the catalytic activities of $\mathrm{Rh}$, by the synthesis of hybrid nanomaterials containing $\mathrm{Rh}$ coupled with $\mathrm{Au}$. We believe that the results presented herein provide insights into the physical and chemical parameters that need to be controlled to optimize the HER performance in Rh NPs via plasmonic excitation in the visible range and may inspire the design and development of $\mathrm{Rh}$-based nanomaterials toward this and other plasmonically enhanced catalytic applications. Possible future directions include other NP designs such as bimetallic systems that enable decreased $\mathrm{Rh}$ contents in the form of alloys or single-atom alloys (containing $\mathrm{Rh}$ as the single-atom components at the $\mathrm{Au}$ surface) and an under- 
standing of why Au@Rh NPs lead to a stronger interaction with water.

\section{ASSOCIATED CONTENT}

\section{SI Supporting Information}

The Supporting Information is available free of charge at https://pubs.acs.org/doi/10.1021/acscatal.1c02938.

Information on the characterization of the $\mathrm{Au}, \mathrm{Rh}$, and Au@Rh NPs by TEM, XPS, and cyclic voltammetry, study of the electrocatalytic performance by in situ FTIR spectra, performance comparison with other reported HER electrocatalysts, modeling of optical properties, and models for water absorption (PDF)

\section{AUTHOR INFORMATION}

\section{Corresponding Authors}

Pedro H. C. Camargo - Department of Chemistry, University of Helsinki, 00560 Helsinki, Finland; (1) orcid.org/00000002-7815-7919; Email: pedro.camargo@helsinki.fi

Susana Inés Cordoba de Torresi - Instituto de Química Universidade de São Paulo, 05508-080 São Paulo, São Paulo, Brazil; @ orcid.org/0000-0003-3290-172X; Email: storresi@iq.usp.br

\section{Authors}

Maria Paula de Souza Rodrigues - Instituto de Química Universidade de São Paulo, 05508-080 São Paulo, São Paulo, Brazil; (1) orcid.org/0000-0002-3731-2644

André H. B. Dourado - Nonequilibrium Chemical Physics, Department of Physics, Technische Universität München, 85748 Garching, Germany

Leonardo de O. Cutolo - Instituto de Química Universidade de São Paulo, 05508-080 São Paulo, São Paulo, Brazil

Luanna S Parreira - Instituto de Química Universidade de São Paulo, 05508-080 São Paulo, São Paulo, Brazil

Tiago Vinicius Alves - Departamento de Físico-Química, Instituto de Quimica, Universidade Federal da Bahia, 40170115 Salvador, Bahia, Brazil; 이이이.org/0000-0001-91293272

Thomas J. A. Slater - Electron Physical Sciences Imaging Centre, Diamond Light Source Ltd., Oxfordshire OX11 ODE, U.K.; (1) orcid.org/0000-0003-0372-1551

Sarah J. Haigh - Department of Materials, University of Manchester, Manchester M13 9PL, United Kingdom; (ㄱ) orcid.org/0000-0001-5509-6706

Complete contact information is available at:

https://pubs.acs.org/10.1021/acscatal.1c02938

\section{Notes}

The authors declare no competing financial interest.

\section{ACKNOWLEDGMENTS}

The authors thank the Brazilian agencies CNPq and the São Paulo Research Foundation FAPESP (2015/26308-7) for financial support. M.P.d.S.R also thanks the FAPESP for the fellowship granted (2018/16846-0). P.H.C.C. thanks the Jane and Aatos Erkko Foundation, the University of Helsinki, HELSUS, and the Academy of Finland for financial support. The authors thank Diamond Light Source for access and support in use of the electron Physical Science Imaging Centre (Instrument E01 and proposal number NT26559) that contributed to the results presented here.

\section{REFERENCES}

(1) Khare, V.; Nema, S.; Baredar, P. Solar-wind Hybrid Renewable Energy System: A Review. Renewable Sustainable Energy Rev. 2016, 58, 23-33.

(2) Zhao, G.; Rui, K.; Dou, S. X.; Sun, W. Heterostructures for Electrochemical Hydrogen Evolution Reaction: A Review. Adv. Funct. Mater. 2018, 28, 1803291.

(3) Wang, H.; Gao, L. Recent Developments in Electrochemical Hydrogen Evolution Reaction. Curr. Opin. Electrochem. 2018, 7, 714.

(4) Fajrina, N.; Tahir, M. A Critical Review in Strategies to Improve Photocatalytic Water Splitting Towards Hydrogen Production. Int. J. Hydrogen Energy 2019, 44, 540-577.

(5) Zou, X.; Zhang, Y. Noble Metal-Free Hydrogen Evolution Catalysts for Water Splitting. Chem. Soc. Rev. 2015, 44, 5148-5180.

(6) Ahmad, H.; Kamarudin, S. K.; Minggu, L. J.; Kassim, M. Hydrogen from Photo-Catalytic Water Splitting Process: a Review. Renewable Sustainable Energy Rev. 2015, 43, 599-610.

(7) Cheng, N.; Stambula, S.; Wang, D.; Banis, M. N.; Liu, J.; Riese, A.; Xiao, B.; Li, R.; Sham, T.-K.; Liu, L.-M.; Botton, G. A.; Sun, X. Platinum Single-Atom and Cluster Catalysis of the Hydrogen Evolution Reaction. Nat. Commun. 2016, 7, 13638.

(8) Han, Z.; Zhang, R.-L.; Duan, J.-J.; Wang, A.-J.; Zhang, Q.-L.; Huang, H.; Feng, J.-J. Platinum-Rhodium Alloyed Dendritic Nanoassemblies: An all-pH Efficient and Stable Electrocatalyst for Hydrogen Evolution Reaction. Int. J. Hydrogen Energy 2020, 45, 6110-6119.

(9) Ghasemi, S.; Hosseini, S. R.; Nabipour, S.; Asen, P. Palladium Nanoparticles Supported on Graphene as an Efficient Electrocatalyst for Hydrogen Evolution Reaction. Int. J. Hydrogen Energy 2015, 40, 16184-16191.

(10) Linic, S.; Christopher, P.; Ingram, D. B. Plasmonic-Metal Nanostructures for Efficient Conversion of Solar to Chemical Energy. Nat. Mater. 2011, 10, 911-921.

(11) Wu, M.; Chen, W.; Shen, Y.; Huang, F.; Li, C.-H.; Li, S. In Situ Growth of Matchlike $\mathrm{ZnO} / \mathrm{Au}$ Plasmonic Heterostructure for Enhanced Photoelectrochemical Water Splitting. ACS Appl. Mater. Interfaces 2014, 6, 15052-15060.

(12) Kang, Y.; Gong, Y.; Hu, Z.; Li, Z.; Qiu, Z.; Zhu, X.; Ajayan, P. M.; Fang, Z. Plasmonic Hot Electron Enhanced MoS2 Photocatalysis in Hydrogen Evolution. Nanoscale 2015, 7, 4482-4488.

(13) Zhan, Z.; An, J.; Zhang, H.; Hansen, R. V.; Zheng, L. ThreeDimensional Plasmonic Photoanodes Based on Au-Embedded $\mathrm{TiO}_{2}$ Structures for Enhanced Visible-Light Water Splitting. ACS Appl. Mater. Interfaces 2014, 6, 1139-1144.

(14) Wang, H.; Gu, X.-K.; Zheng, X.; Pan, H.; Zhu, J.; Chen, S.; Cao, L.; Li, W.-X.; Lu, J. Disentangling the Size-Dependent Geometric and Electronic Effects of Palladium Nanocatalysts Beyond Selectivity. Sci. Adv. 2019, 5, eaat6413.

(15) Araujo, T. P.; Quiroz, J.; Barbosa, E. C. M.; Camargo, P. H. C. Understanding Plasmonic Catalysis with Controlled Nanomaterials Based on Catalytic and Plasmonic Metals. Curr. Opin. Colloid Interface Sci. 2019, 39, 110-122.

(16) Quiroz, J.; Barbosa, E. C. M.; Araujo, T. P.; Fiorio, J. L.; Wang, Y. C.; Zou, Y. C.; Mou, T.; Alves, T. V.; De Oliveira, D. C.; Wang, B.; Haigh, S. J.; Rossi, L. M.; Camargo, P. H. C. Controlling Reaction Selectivity over Hybrid Plasmonic Nanocatalysts. Nano Lett. 2018, 18, 7289-7297.

(17) Zhou, L.; Martirez, J. M. P.; Finzel, J.; Zhang, C.; Swearer, D. F.; Tian, S.; Robatjazi, H.; Lou, M.; Dong, L.; Henderson, L.; Christopher, P.; Carter, E. A.; Nordlander, P.; Halas, N. J. LightDriven Methane Dry Reforming with Single Atomic Site AntennaReactor Plasmonic Photocatalysts. Nat. Energy 2020, 5 (1), 61-70.

(18) Baffou, G.; Quidant, R. Nanoplasmonics for Chemistry. Chem. Soc. Rev. 2014, 43, 3898-3907.

(19) Aslam, U.; Rao, V. G.; Chavez, S.; Linic, S. Catalytic Conversion of Solar to Chemical Energy on Plasmonic Metal Nanostructures. Nat. Catal. 2018, 1, 656-665. 
(20) Wei, J.; Zhou, M.; Long, A.; Xue, Y.; Liao, H.; Wei, C.; Xu, Z. J. Heterostructured Electrocatalysts for Hydrogen Evolution Reaction under Alkaline Conditions. Nano-Micro Lett. 2018, 10, 75.

(21) Zeradjanin, A. R.; Grote, J.-P.; Polymeros, G.; Mayrhofer, K. J. J. A Critical Review on Hydrogen Evolution Electrocatalysis: ReExploring the Volcano-Relationship. Electroanalysis 2016, 28, 22562269.

(22) Linic, S.; Christopher, P.; Xin, H.; Marimuthu, A. Catalytic and Photocatalytic Transformations on Metal Nanoparticles with Targeted Geometric and Plasmonic Properties. Acc. Chem. Res. 2013, 46, 1890-1899.

(23) Şen, B.; Aygün, A.; Şavk, A.; Akocak, S.; Şen, F. Bimetallic Palladium-Iridium Alloy Nanoparticles as Highly Efficient and Stable Catalyst for the Hydrogen Evolution Reaction. Int. J. Hydrogen Energy 2018, 43, 20183-20191.

(24) Gellé, A.; Jin, T.; de la Garza, L.; Price, G. D.; Besteiro, L. V.; Moores, A. Applications of Plasmon-Enhanced Nanocatalysis to Organic Transformations. Chem. Rev. 2020, 120, 986-1041.

(25) Robatjazi, H.; Bao, J. L.; Zhang, M.; Zhou, L.; Christopher, P.; Carter, E. A.; Nordlander, P.; Halas, N. J. Plasmon-Driven CarbonFluorine $\left(\mathrm{C}\left(\mathrm{sp}_{3}\right)-\mathrm{F}\right)$ Bond Activation with Mechanistic Insights into Hot-Carrier-Mediated Pathways. Nat. Catal. 2020, 3 (7), 564-573.

(26) Swearer, D. F.; Zhao, H.; Zhou, L.; Zhang, C.; Robatjazi, H.; Martirez, J. M. P.; Krauter, C. M.; Yazdi, S.; McClain, M. J.; Ringe, E.; Carter, E. A.; Nordlander, P.; Halas, N. J. Heterometallic Antennareactor Complexes for Photocatalysis. Proc. Natl. Acad. Sci. U. S. A. 2016, 113, 8916-8920.

(27) Camargo, P. H. C.; Cortés, E. Plasmonic Catalysis: from Fundamentals to Applications; Wiley: 2021. DOI: 10.1002/ 9783527826971.

(28) Linic, S.; Chavez, S.; Elias, R. Flow and Extraction of Energy and Charge Carriers in Hybrid Plasmonic Nanostructures. Nat. Mater. 2021, 20 (7), 916-924.

(29) Lou, Z.; Fujitsuka, M.; Majima, T. Pt-Au Triangular Nanoprisms with Strong Dipole Plasmon Resonance for Hydrogen Generation Studied by Single-Particle Spectroscopy. ACS Nano 2016, $10,6299-6305$.

(30) Zheng, Z.; Tachikawa, T.; Majima, T. Single-Particle Study of Pt-Modified Au Nanorods for Plasmon-Enhanced Hydrogen Generation in Visible to Near-Infrared Region. J. Am. Chem. Soc. 2014, 136, 6870-6873.

(31) Li, K.; Hogan, N. J.; Kale, M. J.; Halas, N. J.; Nordlander, P.; Christopher, P. Balancing Near-Field Enhancement, Absorption, and Scattering for Effective Antenna-Reactor Plasmonic Photocatalysis. Nano Lett. 2017, 17, 3710-3717.

(32) Robatjazi, H.; Zhao, H.; Swearer, D. F.; Hogan, N. J.; Zhou, L.; Alabastri, A.; McClain, M. J.; Nordlander, P.; Halas, N. J. PlasmonInduced Selective Carbon Dioxide Conversion on Earth-Abundant Aluminum-Cuprous Oxide Antenna-Reactor Nanoparticles. Nat. Commun. 2017, 8 (1), 1-10.

(33) Swearer, D. F.; Robatjazi, H.; Martirez, J. M. P.; Zhang, M.; Zhou, L.; Carter, E. A.; Nordlander, P.; Halas, N. J. Plasmonic Photocatalysis of Nitrous Oxide into $\mathrm{N}_{2}$ and $\mathrm{O}_{2}$ Using AluminumIridium Antenna-Reactor Nanoparticles. ACS Nano 2019, 13, 80768086.

(34) Zhang, C.; Zhao, H.; Zhou, L.; Schlather, A. E.; Dong, L.; McClain, M. J.; Swearer, D. F.; Nordlander, P.; Halas, N. J. Al-Pd Nanodisk Heterodimers as Antenna-Reactor Photocatalysts. Nano Lett. 2016, 16, 6677-6682.

(35) Mascaretti, L.; Dutta, A.; Kment, Š.; Shalaev, V.M.; Boltasseva, A.; Zbořil, R.; Naldoni, A. Plasmon-Enhanced Photoelectrochemical Water Splitting for Efficient Renewable Energy Storage. Adv. Mater. 2019, 31, 1805513.

(36) Liu, G.; Du, K.; Xu, J.; Chen, G.; Gu, M.; Yang, C.; Wang, K.; Jakobsen, H. Plasmon-Dominated Photoelectrodes for Solar Water Splitting. J. Mater. Chem. A 2017, 5, 4233-4253.

(37) Warren, S. C.; Thimsen, E. Plasmonic Solar Water Splitting. Energy Environ. Sci. 2012, 5, 5133-5146.
(38) Lee, J.; Mubeen, S.; Ji, X.; Stucky, G. D.; Moskovits, M. Plasmonic Photoanodes for Solar Water Splitting with Visible Light. Nano Lett. 2012, 12, 5014-5019.

(39) Tada, H. Overall Water Splitting and Hydrogen Peroxide Synthesis by Gold Nanoparticle-Based Plasmonic Photocatalysts. Nanoscale Adv. 2019, 1, 4238-4245.

(40) Zheng, Z.; Tachikawa, T.; Majima, T. Single-Particle Study of Pt-Modified Au Nanorods for Plasmon-Enhanced Hydrogen Generation in Visible to Near-Infrared Region. J. Am. Chem. Soc. 2014, 136, 6870-6873.

(41) Araujo, T. P.; Quiroz, J.; Barbosa, E. C. M.; Camargo, P. H. C. Understanding Plasmonic Catalysis with Controlled Nanomaterials Based on Catalytic and Plasmonic Metals. Curr. Opin. Colloid Interface Sci. 2019, 39, 110-122.

(42) Watson, A. M.; Zhang, X.; Alcaraz De La Osa, R.; Sanz, J. M.; Gonzaíez, F.; Moreno, F.; Finkelstein, G.; Liu, J.; Everitt, H. O. Rhodium Nanoparticles for Ultraviolet Plasmonics. Nano Lett. 2015, $15,1095-1100$.

(43) Zhang, X.; Li, X.; Zhang, D.; Su, N. Q.; Yang, W.; Everitt, H. O.; Liu, J. Product Selectivity in Plasmonic Photocatalysis For Carbon Dioxide Hydrogenation. Nat. Commun. 2017, 8, 14542.

(44) Zhang, M.; Xu, Y.; Wang, S.; Liu, M.; Wang, L.; Wang, Z.; Li, X.; Wang, L.; Wang, H. Polyethylenimine-Modified Bimetallic Au@ $\mathrm{Rh}$ Core-Shell Mesoporous Nanospheres Surpass Pt for $\mathrm{pH}$-universal Hydrogen Evolution Electrocatalysis. J. Mater. Chem. A 2021, 9, $13080-13086$

(45) Wang, H.; Jiao, S.; Liu, S.; Wang, S.; Zhou, T.; Xu, Y.; Li, X.; Wang, Z.; Wang, L. Mesoporous Bimetallic Au@Rh Core-Shell Nanowires as Efficient Electrocatalysts for $\mathrm{pH}$-universal Hydrogen Evolution. ACS Appl. Mater. Interfaces 2021, 13, 30479-30485.

(46) Kang, Y.; Xue, Q.; Peng, R.; Jin, P.; Zeng, J.; Jiang, J.; Chen, Y. Bimetallic AuRh Nanodendrites Consisting of Au Icosahedron Cores and Atomically Ultrathin Rh Nanoplate Shells: Synthesis and LightEnhanced Catalytic Activity. NPG Asia Mater. 2017, 9, e407.

(47) Guerrero, M.; Than Chau, N. T.; Noel, S.; Denicourt-Nowicki, A.; Hapiot, F.; Roucoux, A.; Monflier, E.; Philippot, K. About the use of Rhodium Nanoparticles in Hydrogenation and Hydroformylation Reactions. Curr. Org. Chem. 2013, 17, 364-399.

(48) Jiang, B.; Li, C.; Dag, Ö.; Abe, H.; Takei, T.; Imai, T.; Hossain, M. S. A.; Islam, M. T.; Wood, K.; Henzie, J.; Yamauchi, Y. Mesoporous Metallic Rhodium Nanoparticles. Nat. Commun. 2017, 8, $1-8$

(49) Wagner, C.; Riggs, W.; Davis, L.; Moulder, J. Handbook of X-ray Photoelectron Spectroscopy; Perkin Elmer Corporation: 1979.

(50) Yumitori, S. Correlation of $\mathrm{C}_{1 \mathrm{~s}}$ Chemical State Intensities with the $\mathrm{O}_{1 \mathrm{~s}}$ Intensity in the XPS Analysis of Anodically Oxidized Glasslike Carbon Samples. J. Mater. Sci. 2000, 35, 139-146.

(51) Amendola, V.; Pilot, R.; Frasconi, M.; Maragò, O. M.; Iatì, M. A. Surface Plasmon Resonance in Gold Nanoparticles: a Review. J. Phys.: Condens. Matter 2017, 29, 203002.

(52) Andolina, C. M.; Dewar, A. C.; Smith, A. M.; Marbella, L. E.; Hartmann, M. J.; Millstone, J. E. Photoluminescent Gold-Copper Nanoparticle Alloys with Composition-Tunable Near-Infrared Emission. J. Am. Chem. Soc. 2013, 135, 5266-5269.

(53) Zettsu, N.; McLellan, J. M.; Wiley, B.; Yin, Y.; Li, Z.-Y.; Xia, Y. Synthesis, Stability, and Surface Plasmonic Properties of Rhodium Multipods, and their use as Substrates for Surface-Enhanced Raman Scattering. Angew. Chem. 2006, 118, 1310-1314.

(54) Gutiérrez, Y.; Alcaraz De La Osa, R.; Ortiz, D.; Saiz, M.; González, F.; Moreno, F. Plasmonics in the Ultraviolet with Aluminum, Gallium, Magnesium and Rhodium. Appl. Sci. 2018, 8, 64.

(55) Millstone, J. E.; Wei, W.; Jones, M. R.; Yoo, H.; Mirkin, C. A. Iodide Ions Control Seed-Mediated Growth of Anisotropic Gold Nanoparticles. Nano Lett. 2008, 8, 2526-2529.

(56) Łosiewicz, B.; Jurczakowski, R.; Lasia, A. Kinetics of Hydrogen Underpotential Deposition at Polycrystalline Rhodium in Acidic Solutions. Electrochim. Acta 2011, 56, 5746-5753.

(57) Cataldi, Z.; Lezna, R. O.; Giordano, M. C.; Arvia, A. J. Voltammetric Study of Polycrystalline Rhodium in Alkaline Solutions 
at Different Temperatures. J. Electroanal. Chem. Interfacial Electrochem. 1989, 261, 61-75.

(58) Nakamura, M.; Kato, H.; Hoshi, N. Infrared Spectroscopy of Water Adsorbed on $\mathrm{M}(111)(\mathrm{M}=\mathrm{Pt}, \mathrm{Pd}, \mathrm{Rh}, \mathrm{Au}, \mathrm{Cu})$ Electrodes in Sulfuric Acid Solution. J. Phys. Chem. C 2008, 112, 9458-9463.

(59) Goyal, A.; Koper, M. T. M. The Interrelated Effect of Cations and Electrolyte $\mathrm{pH}$ on The Hydrogen Evolution Reaction on Gold Electrodes in Alkaline Media. Angew. Chem., Int. Ed. 2021, 60, 13452.

(60) Jiang, B.; Huang, A.; Wang, T.; Shao, Q.; Zhu, W.; Liao, F.; Cheng, Y.; Shao, M. Rhodium/Graphitic-Carbon-Nitride Composite Electrocatalyst Facilitates Efficient Hydrogen Evolution in Acidic and Alkaline Electrolytes. J. Colloid Interface Sci. 2020, 571, 30-37.

(61) Kuo, T. R.; Lee, Y. C.; Chou, H. L.; Swathi, M. G.; Wei, C. Y.; Wen, C. Y.; Chang, Y. H.; Pan, X. Y.; Wang, D. Y. Plasmon-Enhanced Hydrogen Evolution on Specific Facet of Silver Nanocrystals. Chem. Mater. 2019, 31, 3722.

(62) Li, B. B.; Qiao, S. Z.; Zheng, X. R.; Yang, X. J.; Cui, Z. D.; Zhu, S. L.; Li, Z. Y.; Liang, Y. Q. Pd Coated $\mathrm{MoS}_{2}$ Nanoflowers for Highly Efficient Hydrogen Evolution Reaction Under Irradiation. J. Power Sources 2015, 284, 68-76.

(63) Zhang, W.; Wang, S.; Yang, S. A.; Xia, X. H.; Zhou, Y. G. Plasmon of Au Nanorods Activates Metal-Organic Frameworks for both the Hydrogen Evolution Reaction and Oxygen Evolution Reaction. Nanoscale 2020, 12, 17290-17297.

(64) Wang, S. S.; Jiao, L.; Qian, Y.; Hu, W. C.; Xu, G. Y.; Wang, C.; Jiang, H. L. Boosting Electrocatalytic Hydrogen Evolution over Metal-Organic Frameworks by Plasmon-Induced Hot-Electron Injection. Angew. Chem., Int. Ed. 2019, 58, 10713-10717.

(65) Li, D.; Lao, J.; Jiang, C.; Luo, C.; Qi, R.; Lin, H.; Huang, R.; Waterhouse, G. I. N.; Peng, H. Plasmonic Au Nanoparticle-Decorated $\mathrm{Bi}_{2} \mathrm{Se}_{3}$ Nanoflowers with Outstanding Electrocatalytic Performance for Hydrogen Evolution. Int. J. Hydrogen Energy 2019, 44, 3087630884.

(66) Jiang, W.; Wu, X.; Chang, J.; Ma, Y.; Song, L.; Chen, Z.; Liang, C.; Liu, X.; Zhang, Y. Integrated Hetero-Nanoelectrodes for PlasmonEnhanced Electrocatalysis of Hydrogen Evolution. Nano Res. 2021, $14,1195-1201$.

(67) Zhao, J.; Nguyen, S. C.; Ye, R.; Ye, B.; Weller, H.; Somorjai, G. A.; Alivisatos, A. P.; Toste, F. D. A Comparison of Photocatalytic Activities of Gold Nanoparticles Following Plasmonic and Interband Excitation and a Strategy for Harnessing Interband Hot Carriers for Solution Phase Photocatalysis. ACS Cent. Sci. 2017, 3, 482-488.

(68) Wilson, A. J.; Mohan, V.; Jain, P. K. Mechanistic Understanding of Plasmon-Enhanced Electrochemistry. J. Phys. Chem. C 2019, 123, 29360-29369.

(69) Trasatti, S. Work Function, Electronegativity, and Electrochemical Behaviour of Metals. II. Potentials of Zero Charge and "Electrochemical" Work Functions. J. Electroanal. Chem. Interfacial Electrochem. 1971, 33, 351-378.

(70) Trasatti, S. Work Function, Electronegativity, and Electrochemical Behaviour of Metals. III. Electrolytic Hydrogen Evolution in Acid Solutions. J. Electroanal. Chem. Interfacial Electrochem. 1972, 39, $163-184$.

(71) Petrii, O. A. Zero Charge Potentials of Platinum Metals and Electron Work Functions (Review). Russ. J. Electrochem. 2013, 49, 401-422.

(72) Nørskov, J. K.; Bligaard, T.; Logadottir, A.; Kitchin, J. R.; Chen, J. G.; Pandelov, S.; Stimming, U. Trends in the Exchange Current for Hydrogen Evolution. J. Electrochem. Soc. 2005, 152, J23.

(73) Zeradjanin, A. R.; Vimalanandan, A.; Polymeros, G.; Topalov, A. A.; Mayrhofer, K. J. J.; Rohwerder, M. Balanced Work Function as a Driver for Facile Hydrogen Evolution Reaction - Comprehension and Experimental Assessment of Interfacial Catalytic Descriptor. Phys. Chem. Chem. Phys. 2017, 19, 17019-17027.

(74) Dubouis, N.; Grimaud, A. The Hydrogen Evolution Reaction: from Material to Interfacial Descriptors. Chem. Sci. 2019, 10, 91659181.

(75) Björneholm, O.; Hansen, M. H.; Hodgson, A.; Liu, L. M.; Limmer, D. T.; Michaelides, A.; Pedevilla, P.; Rossmeisl, J.; Shen, H.;
Tocci, G.; Tyrode, E.; Walz, M. M.; Werner, J.; Bluhm, H. Water at Interfaces. Chem. Rev. 2016, 116, 7698-7726.

(76) Dourado, A. H. B.; Silva, N. A.; Munhos, R. L.; Del Colle, V.; Arenz, M.; Varela, H.; Córdoba, S. I. de Torresi, Influence of Anion Chaotropicity on The $\mathrm{SO}_{2}$ Oxidation Reaction: when Spectator Species Determine the Reaction Pathway. ChemElectroChem. 2020, 7, 1843-1850.

(77) Dourado, A. H. B.; Munhos, R. L.; Silva, N. A.; Del Colle, V.; Carvalho, G. G. A.; Oliveira, P. V.; Arenz, M.; Varela, H.; Córdoba De Torresi, S. I. Opportunities and Knowledge Gaps of $\mathrm{SO}_{2}$ Electrocatalytic Oxidation for $\mathrm{H}_{2}$ Electrochemical Generation. ACS Catal. 2019, 8136-8143.

(78) Maier, T.L.; Golibrzuch, M.; Mendisch, S.; Schindler, W.; Becherer, M.; Krischer, K. Lateral Silicon Oxide/Gold Interfaces Enhance The Rate of Electrochemical Hydrogen Evolution Reaction in Alkaline Media. J. Chem. Phys. 2020, 152, 154705.

(79) Liang, Z.; Chen, W.; Liu, J.; Wang, S.; Zhou, Z.; Li, W.; Sun, G.; Xin, Q. FT-IR Study of the Microstructure of Nafion ${ }^{\circledR}$ Membrane. J. Membr. Sci. 2004, 233, 39-44.

(80) Kunimatsu, K.; Yoda, T.; Tryk, D. A.; Uchida, H.; Watanabe, M. In Situ ATR-FTIR Study of Oxygen Reduction at the Pt/Nafion Interface. Phys. Chem. Chem. Phys. 2010, 12, 621-629.

(81) Xue, W.; He, H.; Zhu, J.; Yuan, P. FTIR Investigation of CTAB-Al-montmorillonite Complexes. Spectrochim. Acta, Part A 2007, 67, 1030-1036.

(82) Garcia-Araez, N.; Rodriguez, P.; Bakker, H. J.; Koper, M. T. M. Effect of the Surface Structure of Gold Electrodes on the Coadsorption of Water and Anions. J. Phys. Chem. C 2012, 116, 4786-4792.

(83) Thiel, P. A.; Madey, T. E. The Interaction of Water with Solid Surfaces: Fundamental Aspects. Surf. Sci. Rep. 1987, 7, 211-385.

(84) Garcia-Araez, N.; Rodriguez, P.; Navarro, V.; Bakker, H. J.; Koper, M. T. M. Structural Effects on Water Adsorption on Gold Electrodes. J. Phys. Chem. C 2011, 115, 21249-21257.

(85) Dunwell, M.; Yan, Y.; Xu, B. A Surface-Enhanced Infrared Absorption Spectroscopic Study of $\mathrm{pH}$ Dependent Water Adsorption on Au. Surf. Sci. 2016, 650, 51-56.

(86) Wang, X.; Xu, C.; Jaroniec, M.; Zheng, Y.; Qiao, S.Z. Anomalous Hydrogen Evolution Behavior in High-pH Environment Induced by Locally Generated Hydronium Ions. Nat. Commun. 2019, 10,4876 .

(87) Ataka, K. I.; Yotsuyanagi, T.; Osawa, M. Potential-Dependent Reorientation of Water Molecules at an Electrode/Electrolyte Interface Studied by Surface-Enhanced Infrared Absorption Spectroscopy. J. Phys. Chem. 1996, 100, 10664-10672.

(88) Stuve, E. M. Ionization of Water in Interfacial Electric Fields: an Electrochemical View. Chem. Phys. Lett. 2012, 519-520, 1-17.

(89) Zeradjanin, A. R.; Polymeros, G.; Toparli, C.; Ledendecker, M.; Hodnik, N.; Erbe, A.; Rohwerder, M.; La Mantia, F. What is the Trigger for the Hydrogen Evolution Reaction? - Towards Electrocatalysis Beyond the Sabatier Principle. Phys. Chem. Chem. Phys. 2020, 22, 8768-8780.

(90) Osawa, M.; Tsushima, M.; Mogami, H.; Samjeské, G.; Yamakata, A. Structure of Water at the Electrified Platinum-Water Interface: a Study by Surface-Enhanced Infrared Absorption Spectroscopy. J. Phys. Chem. C 2008, 112, 4248-4256.

(91) Chen, X.; McCrum, I. T.; Schwarz, K. A.; Janik, M. J.; Koper, M. T. M. Co-Adsorption of Cations as the Cause of the Apparent $\mathrm{pH}$ Dependence of Hydrogen Adsorption on a Stepped Platinum SingleCrystal Electrode. Angew. Chem., Int. Ed. 2017, 56, 15025-15029. 